\title{
Review Article \\ Dysfunctional High-Density Lipoprotein: An Innovative Target for Proteomics and Lipidomics
}

\author{
Juan Salazar, Luis Carlos Olivar, Eduardo Ramos, Mervin Chávez-Castillo, \\ Joselyn Rojas, and Valmore Bermúdez \\ Endocrine-Metabolic Research Center, "Dr. Félix Gómez," Faculty of Medicine, University of Zulia, Zulia State, \\ Maracaibo 4004, Venezuela \\ Correspondence should be addressed to Joselyn Rojas; rojas.joselyn@gmail.com
}

Received 23 August 2015; Revised 12 October 2015; Accepted 12 October 2015

Academic Editor: Matti Jauhiainen

Copyright (C) 2015 Juan Salazar et al. This is an open access article distributed under the Creative Commons Attribution License, which permits unrestricted use, distribution, and reproduction in any medium, provided the original work is properly cited.

High-Density Lipoprotein-Cholesterol (HDL-C) is regarded as an important protective factor against cardiovascular disease, with abundant evidence of an inverse relationship between its serum levels and risk of cardiovascular disease, as well as various antiatherogenic, antioxidant, and anti-inflammatory properties. Nevertheless, observations of hereditary syndromes featuring scant HDL-C concentration in absence of premature atherosclerotic disease suggest HDL-C levels may not be the best predictor of cardiovascular disease. Indeed, the beneficial effects of HDL may not depend solely on their concentration, but also on their quality. Distinct subfractions of this lipoprotein appear to be constituted by specific protein-lipid conglomerates necessary for different physiologic and pathophysiologic functions. However, in a chronic inflammatory microenvironment, diverse components of the HDL proteome and lipid core suffer alterations, which propel a shift towards a dysfunctional state, where HDL-C becomes proatherogenic, prooxidant, and proinflammatory. This heterogeneity highlights the need for further specialized molecular studies in this aspect, in order to achieve a better understanding of this dysfunctional state; with an emphasis on the potential role for proteomics and lipidomics as valuable methods in the search of novel therapeutic approaches for cardiovascular disease.

\section{Introduction}

Cardiovascular disease (CVD) constitutes the worldwide leading cause of morbidity and mortality, unequivocally representing an alarming public health problem [1]. Various conditions, termed risk factors, are associated with the onset and progression of CVD, including hypertension, obesity, and dyslipidemias [2, 3], framed in a lifestyle characterized by several deleterious habits, such as fat- and carbohydrate-rich diets, smoking, and physical inactivity [4], augmenting the probability of suffering CVD. Among these factors, dyslipidemias emerge as some of the most significant etiopathogenic components given their close link to the atherosclerotic process, being considered the main therapeutic target in the management of CVD [5].

Dyslipidemias are disorders of lipid metabolism, manifested as an abnormal increase or decrease of serum lipids. Diverse reports support a beneficial role for High-Density Lipoproteins (HDL) in regard to cardiovascular health, boasting powerful antiatherogenic properties $[6,7]$. These are mediated by a phenomenon known as reverse cholesterol transport (RCT), through which cholesterol molecules are carried from cells in vascular walls and other organs to the liver, where they may be reutilized or excreted [8]. Likewise, other antiatherogenic attributes comprise inhibition of monocyte adherence to the endothelium and monocytes migration to the arterial intima, prevention of vascular thrombosis, stimulation of endothelial repair, and many others [9]. Epidemiologic studies like the Cooperative Lipoprotein Phenotyping Study [10] and the Framingham Heart Study [11] have identified HDL cholesterol (HDL-C) to be intimately related to the atherosclerotic process, where serum HDL-C concentrations have been demonstrated to have an inverse relationship with CVD incidence. Indeed, in the latter, a $10 \mathrm{mg} / \mathrm{dL}$ increase in HDL-C concentration has been associated with not only lower cardiovascular mortality, but also decreased all-cause mortality [12].

In spite of these findings, there is conflictive evidence regarding the "protective" role of HDL-C in cardiovascular 


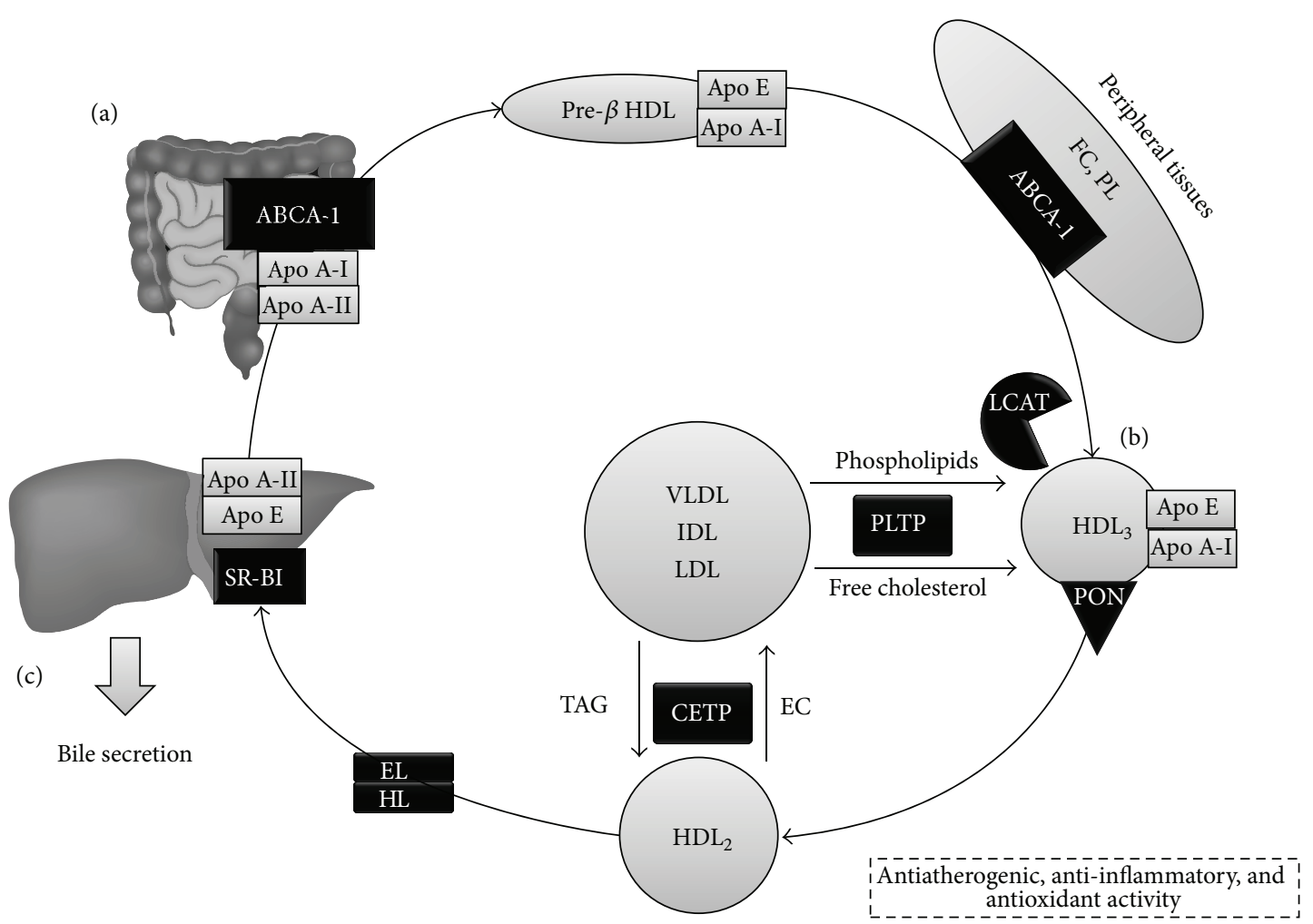

FIGURE 1: HDL metabolism and main components implicated in their antiatherogenic-anti-inflammatory functions. HDL metabolism consists of 3 phases. (a) Synthesis occurs in the liver and intestine, originating discoid or pre- $\beta$ HDL. This subpopulation initiates RCT in peripheral tissues, mediated by Apo A-I binding to ABCA-1 and LCAT, resulting in HDL rich in cholesteryl esters. (b) $\mathrm{HDL}_{3}$ are the first to form, which continue cholesterol capture in various tissues. Likewise, CETP transfers TAG to HDL, whereas PLTP mediates transfer of phospholipids and free cholesterol, increasing the size of the particles, yielding $\mathrm{HDL}_{2}$. (c) Finally, HDL undergos exclusion through SR-B1 in hepatocytes, for either biliary secretion or formation of new lipoproteins. FC: free cholesterol; PL: phospholipids; ABCA-1: ATP-binding cassette transporter A-1; LCAT: Lecithin-Cholesterol Acyltransferase; PON: Paraoxonase; CETP: cholesteryl ester transfer protein; HL: hepatic lipase; EL: endothelial lipase; HDL: High-Density Lipoprotein; SR-B1: Scavenger Receptor B1.

health: certain hereditary syndromes featuring scant HDL-C levels have been shown not to display early atherosclerosis [13-15]; and very high levels of this lipoprotein do not appear to grant additional benefits [16]. Indeed, current knowledge suggests the biologic activity of HDL may depend on both their quantity and their quality, as alterations in various structural components lead to a state of dysfunction independently of their serum concentration [17]. Given the epidemic CVD has grown into, and the rising scientific interest in HDL as a therapeutic target, it is necessary to understand the molecular aspects underlying their dysfunction and possible approaches for their evaluation.

\section{Metabolism of High-Density Lipoprotein-Cholesterol}

Structurally, HDL units may be described as macromolecular pseudomicellar complexes, characterized by exhibiting the greatest density $(1.063-1.21 \mathrm{~g} / \mathrm{mL})$ and smallest size $(4-13 \mathrm{~nm})$ among all lipoproteins [18]. Multiple HDL molecules may associate, forming a completely hydrophobic nucleus rich in cholesteryl esters (CE), covered by a layer of amphipathic lipids and proteins. HDL molecules also possess important quantities of $\mathrm{CE}$ on the lipoprotein surfaces employed for interaction with the enzymes intervening in their metabolism [19]. These mediators include hepatic lipase, cholesteryl ester transfer protein (CETP), Phospholipid Transfer Protein (PLTP), and Lecithin-Cholesterol Acyltransferase (LCAT) [20-22].

Metabolism of HDL is organized in three fundamental stages: formation, maturation, and exclusion (Figure 1). Initially, HDL are synthesized and secreted from the liver and intestine as nascent pre- $\beta-1$ HDL or discoid HDL particles, conformed predominantly by apolipoprotein A-I (Apo A-I) and phospholipids. These particles then arrive at peripheral tissues and remove free cholesterol (FC) as part of RCT [23]. Besides, these lipid-poor, Apo A-I-rich, nascent HDL particles are capable of removing FC through the ATP-binding cassette transporter A-1 (ABCA-1), which transfers these lipids towards the interior of the pre- $\beta-1$ lipoprotein [24]. Finally, LCAT acts by esterifying FC present in these pre- $\beta$ 1 lipoproteins, originating CE-rich, mature HDL [25], while ATP-binding cassette transporter G-1 (ABCG-1) mediates cholesterol efflux to these mature HDLs [26].

In this stage, CE now occupy and contribute to the lipid core of the micelle, marking the transition from nascent HDL 
into small $\mathrm{HDL}_{3}$, which can bind to their mature, spherical counterparts in the liver and intestines. Due to their low cholesterol content, small $\mathrm{HDL}_{3}$ are able to continue collecting excess cholesterol in cell membranes [26]. Once no substrates for LCAT remain, $\mathrm{HDL}_{3}$ begin accepting phospholipids, cholesterol, and apoproteins from other lipoproteins, derived from the activity of lipoprotein lipase on chylomicrons and very low-density lipoprotein (VLDL). Indeed, PLTP mediates the transfer of excess phospholipids from the surface of TAG-rich lipoproteins to HDL, facilitating the formation of lipoprotein remnants and contributing to HDL maturation, which further increase in size and become phospholipid-rich $\mathrm{HDL}_{2}$ [27]. PLTP also drives a phenomenon termed conversion [28], which involves fusion of several HDL particles, generating larger HDL with concomitant production of small lipid-poor Apo A-I/phospholipid complexes [29]. Finally, PLTP is also an essential component in RCT, not only by facilitating cholesterol efflux from peripheral tissues [30], but also by yielding pre- $\beta 2 \mathrm{HDL}$, lipid-poor particles during conversion, which act as initial acceptors of this cholesterol efflux [31], and by stabilizing ABCA-1, thus promoting phospholipid and cholesterol traffic by this intermediary [32].

Phospholipid-rich $\mathrm{HDL}_{2}$ are also LCAT substrates, allowing removal of FC and phosphatidylcholine (PC) excess accumulated in cell surfaces; this results in an increase of lipoprotein volume, reflecting growing quantities of CE in their core [33]. In addition, CETP also catalyzes the exchange of CE for triacylglycerides (TAG) from $\mathrm{HDL}_{2}$ to VLDL $[33,34]$, which is essential for maintaining a hydrophobic environment in the core [35]. CETP seems to achieve this through three powerful mechanisms [7]. Firstly, CETP can act freely as a lipid transporter between lipoproteins. It is also involved in the assembly of ternary donor-acceptor complexes with lipoproteins. Lastly, CETP also participates in the arrangement of other distinct ternary complexes, featuring CETP dimers which aid in the formation of binding sites for lipoproteins [34]. These TAG-rich HDL are now optimal targets for hepatic and endothelial lipases, which hydrolyze TAG and phospholipids, thus favoring $\mathrm{HDL}$ catabolism, retransitioning from $\mathrm{HDL}_{2}$ to $\mathrm{HDL}_{3}$ and pre- $\beta$ HDL [36].

Lastly, during exclusion, HDLs release cholesterol directly to the liver and steroidogenic tissues through selective HDL capture mediated by Scavenger Receptor class B type I (SR$\mathrm{BI})$, releasing particles integrated into its structure without undergoing complete degradation [35]. This process delivers cholesterol for synthesis and secretion of new lipoproteins and biliary excretion in the liver, as well as synthesis of steroid hormones in steroidogenic tissues [37]. Ulterior catabolism of HDL particles occurs mainly in the liver and kidney, finalizing their life cycle [38].

Another pathway involved in HDL metabolism is endocytosis, facilitated by SR-BI in peripheral tissues, followed by resecretion-now rich in cholesterol-to the vascular medium, contributing to cholesterol efflux [39, 40]. This mechanism is very important in the origin of foamy cells in atheromatous plaques [41]. At the intracellular level, the first metabolic checkpoint is the Golgi apparatus, requiring microtubule indemnity [42]. Nevertheless, lysosomal degradation of HDL appears to be low [43]; thus, endocytic activity seems to be oriented towards selective lipid modification of HDL, lowering its CE and FC contents [40].

\section{Serum HDL-C Levels and Cardiovascular Disease}

Abundant clinical and epidemiological studies have consistently proved an inverse relationship between HDL-C concentration and cardiovascular risk (CVR) (Table 1). In the Framingham Heart Study, Wilson et al. described low HDL$\mathrm{C}$ levels to entail a 3-4 times greater risk for cardiovascularcause mortality, after following up over 2000 subjects aged $>50$ years for 12 years [12]. Moreover, the Emerging Risk Factors Collaboration workgroup have conducted a metaanalysis on 68 prospective studies, which supports this link between HDL-C and CVR following adjustment for other variables such as non-HDL cholesterol, TAG, and smoking [44]. Indeed, a $15 \mathrm{mg} / \mathrm{dL}$ increase in HDL-C levels appears to grant a $22 \%$ decrease in CVR, independently of TAG levels [44]. Similarly, the Münster Heart Study has reported dyslipidemias to be the factor most tightly correlated with coronary events, and HDL-C concentration in particular appears to be an important predictor of atherosclerotic disease $[45,46]$, in harmony with findings from the INTERHEART Study, which has also reported dyslipidemias-especially low HDL$\mathrm{C}$ - to be key predictors of CVR, based on estimations with ApoB/ApoAI index [47].

Nevertheless, various clinical and genetic studies have suggested HDL-C not to be the best predictors of CVR in certain contexts (Table 2 ), as originally ascertained in reports on the effects of torcetrapib, a CETP inhibitor. Pilot studies offered very promising outcomes, describing 60-100\% increases in HDL-C concentration with this drug [48]. These were later supported by a large multicentric clinical trial, the ILLUMINATE study, which found a $72.1 \%$ rise in HDL$\mathrm{C}$ levels in subjects on this agent $(p<0.001)$ [16]. However, such increase was subsequently proved ineffective at deterring progression of atherosclerosis and associated with higher CVR (HR: 1.58; IC: 1.14-2.19; $p=0.006$ ) [16, 49-51]. The trial suffered unforeseen premature termination due to a marked increase in subject mortality, despite the significant rise in HDL-C concentration. Although the causes behind this failure remain uncertain, the most prominent hypothesis attributes defects to torcetrapib and not CETP inhibition itself, presumably through direct vascular toxicity, promotion of hypertension, or interactions with the renin-angiotensinaldosterone system [51]. Current studies aim at discerning the effects of other CETP inhibitors [52].

In the field of genetic research, studies in monozygotic twins have found $40-60 \%$ of variation in HDL-C levels to be genetically determined [53]. Roughly, 10 genes have been confirmed to participate in the regulation of $\mathrm{HDL}-\mathrm{C}$ concentration in humans, almost all being responsible for Mendelian hereditary disorders that feature disturbances of HDL-C levels [54]. Research has also been directed at establishing associations between specific single-nucleotide polymorphisms (SNP) or haplotypes with either higher or 
TABLE 1: HDL-C as a good predictor of cardiovascular risk.

\begin{tabular}{|c|c|c|}
\hline Author [reference] & Methodology & Conclusions \\
\hline Barter et al. [6] & $\begin{array}{l}\text { Post hoc analysis of data from the Treating to New } \\
\text { Targets Study, a multicentric, randomized, } \\
\text { double-blind study which assessed the predictive } \\
\text { value of HDL-C in } 9,770 \text { subjects with established } \\
\text { CVD on statin therapy. }\end{array}$ & $\begin{array}{l}\text { Based on HDL-C quintiles, a multivariate analysis } \\
\text { revealed individuals with HDL-C }>55 \mathrm{mg} / \mathrm{dL} \text { to have a } \\
\text { lower risk of cardiovascular mortality than subjects } \\
\text { with HDL-C }<38 \mathrm{mg} / \mathrm{dL} \text { (HR: } 0.75 \text {; IC } 95 \% \text { : } 0.60-0.95 \text { ). } \\
\text { In subjects on statin therapy, the best lipid predictor for } \\
\text { CVD was HDL-C, even when LDL-C }<70 \mathrm{mg} / \mathrm{dL} \text {. }\end{array}$ \\
\hline Castelli et al. [10] & $\begin{array}{l}\text { Multicentric case-control study with } 6859 \text { subjects of } \\
\text { diverse ethnicities from the Cooperative Lipoprotein } \\
\text { Phenotyping Study. }\end{array}$ & $\begin{array}{l}\text { HDL-C concentration was significantly higher in } \\
\text { subjects without established CVD. An inverse } \\
\text { correlation was ascertained between these factors, } \\
\text { without significant variation after adjustment for total } \\
\text { cholesterol, LDL-C, and TAG levels. }\end{array}$ \\
\hline Gordon et al. [11] & $\begin{array}{l}\text { Prospective report from the Framingham Heart } \\
\text { Study, with 2,815 subjects aged } 49-82 \text { years, whose } \\
\text { serum lipids were quantified throughout a } 4 \text {-year } \\
\text { follow-up period in order to evaluate cardiovascular } \\
\text { mortality. }\end{array}$ & $\begin{array}{l}142 \text { individuals developed CVD ( } 79 \text { males, } 63 \text { females), } \\
\text { with HDL-C being the best CVR predictor. These } \\
\text { variables shared an inverse correlation in both genders, } \\
\text { even after adjustment for multiple other risk factors. }\end{array}$ \\
\hline Wilson et al. [12] & $\begin{array}{l}\text { Prospective report from the Framingham Heart } \\
\text { Study, with } 2,748 \text { individuals aged } 50-79 \text { years after a } \\
12 \text {-year follow-up period. }\end{array}$ & $\begin{array}{l}\text { An inverse relationship was identified between HDL-C } \\
\text { levels and coronary artery disease mortality in both } \\
\text { genders }(p>0.05) \text {. HDL-C was found to be the best } \\
\text { predictor of cardiovascular mortality. }\end{array}$ \\
\hline $\begin{array}{l}\text { Emerging Risk } \\
\text { Factors Collaboration } \\
{[44]}\end{array}$ & $\begin{array}{l}\text { 302,430 subjects from the Emerging Risk Factors } \\
\text { Collaboration Study data without history of coronary } \\
\text { artery disease were studied to analyze the association } \\
\text { between serum lipids and CVR. }\end{array}$ & $\begin{array}{l}\text { A strong inverse association was found between risk of } \\
\text { coronary artery disease and HDL-C levels after } \\
\text { adjusting for nonlipid risk factors (HR: } 0.71 \text {;C 95\%: } \\
0.68-0.75 \text { ) and even after adjustment for non-HDL } \\
\text { cholesterol (HR: 0.78; IC 95\%: 0.74-0.82). }\end{array}$ \\
\hline Assmann et al. [45] & $\begin{array}{l}\text { The incidence of coronary artery disease was } \\
\text { determined in } 4,559 \text { male subjects aged } \geq 40 \text { years } \\
\text { from the Prospective Cardiovascular Münster Study } \\
\text { over a 6-year follow-up period. }\end{array}$ & $\begin{array}{l}\text { Univariate analysis revealed a significant inverse } \\
\text { relationship between CAD and HDL-C }(p>0.001) \text {, } \\
\text { even after adjustment for several other risk factors. }\end{array}$ \\
\hline
\end{tabular}

lower HDL-C, in the presence or absence of atherosclerosis [55]. Variations of Apo A-I are among the most prominent: numerous mutations of the APOAI gene have been observed to propitiate a dose-dependent reduction in HDL-C levels, which may be virtually absent in homozygous individuals and $50 \%$ lower in their heterozygous counterparts [56]. Notoriously, although APOAI mutations lower HDL-C concentration, this is not consistently accompanied by higher CVR [57]. The R173C-Milano mutation represents an illustrative case in this respect: despite being linked to dramatically lower HDL$\mathrm{C}$ levels, it appears to enhance their antiatherogenic assets, hinting at a gain-of-function effect [58].

Multiple other studies pinpoint the $A B C A-1$ gene as the principal determinant of serum HDL-C levels [59]. Broad arrays of SNP have been identified for this gene, yet these rarely suppress its functionality [60]. Likewise, polymorphisms of the promoting gene of hepatic lipase have been found to impair its activity, thus significantly elevating HDLC levels. Paradoxically, this genotype implicates a $40-50 \%$ increase in CVR [61]. Similarly, a SNP in the endothelial lipase gene (LIPG 396Ser allele) has also been shown to be linked with increased HDL-C concentration, without effect on CVR [62]. Finally, a mutation of Apo A-I has been described to be able to predict CVR even in absence of low HDL-C in the Copenhagen City Heart Study [63]. Therefore, Apo A-I may be a better predictor than the macromolecular complex in whole. Furthermore, because adequate HDL functionality strongly depends on Apo A-I, partial or total mutations of this component may considerably affect RCT [64] and, by extension, CVR. In the Dallas Heart Study, high cholesterol efflux capacity was inversely associated with cardiovascular mortality after adjusting for traditional cardiovascular risk factors, HDL-C concentration, and HDL particle concentration $(\mathrm{HR}=0.33$; 95\% CI $=0.19-0.55 ; p<$ 0.05), whereas baseline HDL-C levels did not show such association in a similar model [65].

\section{A Molecular Look into Dysfunctional High-Density Lipoproteins}

The protein components of HDL constitute most of its complex macromolecular framework (55-60\% of the particles' mass), accounting for structural apolipoproteins, enzymes, and their corresponding cofactors. The remaining proportion is composed of lipids, chiefly amphipathic in character (phospholipids and FC) [66]. These macromolecules show ample heterogeneity in regard to chemical composition, metabolism, and biologic activity, as a result of the continuous exchange of both apoproteins and lipids from the core occurring both in peripheral tissues and in circulation $[66,67]$. This dynamism is enabled by the "flexibility" displayed by $\alpha$ helices in Apo A-I in response to the structural modifications suffered in each subfraction [68]. 
TABLE 2: HDL-C as a poor predictor of cardiovascular risk.

\begin{tabular}{ll}
\hline Author [reference] & Methodology \\
\hline & $\begin{array}{l}\text { Randomized, double-blind study on 15,607 subjects } \\
\text { with high CVR, who received (a) atorvastatin + } \\
\text { torcetrapib or (b) atorvastatin + placebo. }\end{array}$ \\
\hline
\end{tabular}

Prospective, multicentric, randomized, double-blind study on 1,188 patients with CAD who underwent

Nissen et al. [49] intravascular ultrasonography and received (a) atorvastatin + torcetrapib or (b) atorvastatin + placebo.
Conclusions

Although treatment with torcetrapib raised HDL-C $72 \%$ from the baseline $(p<0.001)$, it entailed an increase in cardiovascular mortality in these subjects (HR: 1.25 ; 95\% CI: $1.09-1.44$; $p=0.001$ ).

Subjects on atorvastatin + torcetrapib had a $61 \%$ increase in HDL-C and a $20 \%$ decrease in LDL-C levels when compared to the group on atorvastatin + placebo. However, the former also suffered a greater rise in blood pressure (21.3\% versus $8.2 \%$ ) and incidence of hypertensive cardiovascular events $(23.7 \%$ versus $10.6 \%$ ), without significant differences in progression of atherosclerosis, as evaluated by intravascular ultrasonography.

850 heterozygotes with familial hypercholesterolemia were treated with 20,40 , or $80 \mathrm{mg}$ of atorvastatin for a 4-week period, followed by (a) atorvastatin monotherapy or (b) atorvastatin + torcetrapib $60 \mathrm{mg}$ for 24 months, and underwent ultrasonography for evaluation of intima-media thickness.

Kastelein et al. [50]

Mendelian randomization study which evaluated the association between the LIPG Asn396Ser SNP and incident myocardial infarction in 50,763 participants from six prospective cohort studies and case-control studies involving an additional 16,685 cases of myocardial infarction and 48,872 controls and proposed a genetic score combining 14 common SNP that exclusively associate with HDL cholesterol and then tested this score in up to 12,482 cases of myocardial infarction and 41,331 controls.

HDL-C levels were significantly higher in the atorvastatin + torcetrapib group $(81.5 \pm 22.6 \mathrm{mg} / \mathrm{dL}$ versus $52.4 \pm 13.5 \mathrm{mg} / \mathrm{dL} ; p<0.001$ ), who also displayed lower LDL-C and TAG concentrations. Nevertheless, those on monotherapy were found to have greater intima-media thickness in the common carotid artery.

The LIPG Asn396Ser allele had a prevalence of 2.6\% and was associated with increased HDL-C, without effect on LDL-C y TAG. In meta-analysis, carrier status for Asn396Ser was associated with an increase of roughly $0.29 \mathrm{SD}$ units in HDL-C $\left(p=8 \times 10^{-13}\right)$, with no associations to other risk factors. Nevertheless, this allele was not associated with myocardial infarction (OR: 0.99; 95\% CI 0.88-1.11, $p=0.85$ ), without significant heterogeneity among the studies included $(p>0.05)$. Finally, a 1 SD increase in HDL-C due to genetic score was not associated with risk of myocardial infarction (OR: 0.93 ; 95\% CI: 0.68-1.26, $p=0.63$ ).

The APOAl gene was resequenced in 190 subjects, evaluating the effects of mutations on HDL-C levels, risk of ischemic heart disease, myocardial infarction, and mortality in 10,440 individuals from the prospective Copenhagen City Heart Study, who were followed for 31 years. Results were validated in an independent case-control study with 16,035 subjects.

Multiethnic, population-based cohort study on 2,416 adults free from CVD who were participants in the Rohatgi et al. [65] Dallas Heart Study, where the association between cholesterol efflux capacity and CVD incidence was assessed.

The A164S mutation was found to be a predictor of ischemic heart disease (HR: 32; 95\% CI: 1.6-6.5), myocardial infarction (HR: 5.5; CI 95\% 2.6-11.7), and mortality (HR: 2.5; 95\% CI: 1.3-4.8) in heterozygotes, in comparison to noncarriers. A164S heterozygotes also showed normal levels of Apo A-I, as well as HDL-C and other serum lipids.

HDL-C levels were found to be unrelated to CVD incidence after adjustment for traditional cardiovascular risk factors. Cholesterol efflux capacity was associated with lower CVR, even after adjustment for HDL-C concentration, HDL particle concentration, and traditional cardiovascular risk factors (HR: 0.33; 95\% CI: 0.19-0.55).

21 subjects with the Apo A-IMilano mutation were compared with age- and sex-matched control subjects from the same kindred and with 2 series of matched subjects with primary

Sirtori et al. [247] hypoalphalipoproteinemia (HDL-C levels under the 10 th percentile for their gender and age), regarding ultrasonographic findings in carotid arteries.

Subjects with hypoalphalipoproteinemia had greater intima-media thickness $(0.86 \pm 0.25 \mathrm{~mm})$ than the control group $(0.64 \pm 0.12 \mathrm{~mm})$ and subjects with the Apo A-IMilano mutation $(0.63 \pm 0.10 \mathrm{~mm}) ; p<0.005$. Moreover, subjects with hypoalphalipoproteinemia had a significantly higher prevalence of atherosclerotic plaques than both of the other groups, despite the lower HDL-C levels $(19.8 \pm 9.8 \mathrm{mg} / \mathrm{dL}, p<0.05)$.

Subjects on dalcetrapib had a $31-40 \%$ increase in HDL-C levels, with minimal effects on LDL-C. Compared to placebo, the dalcetrapib group did not show significantly higher CVR (HR: 1.04; 95\% IC: $0.93-1.15, p=0.52$ ). 


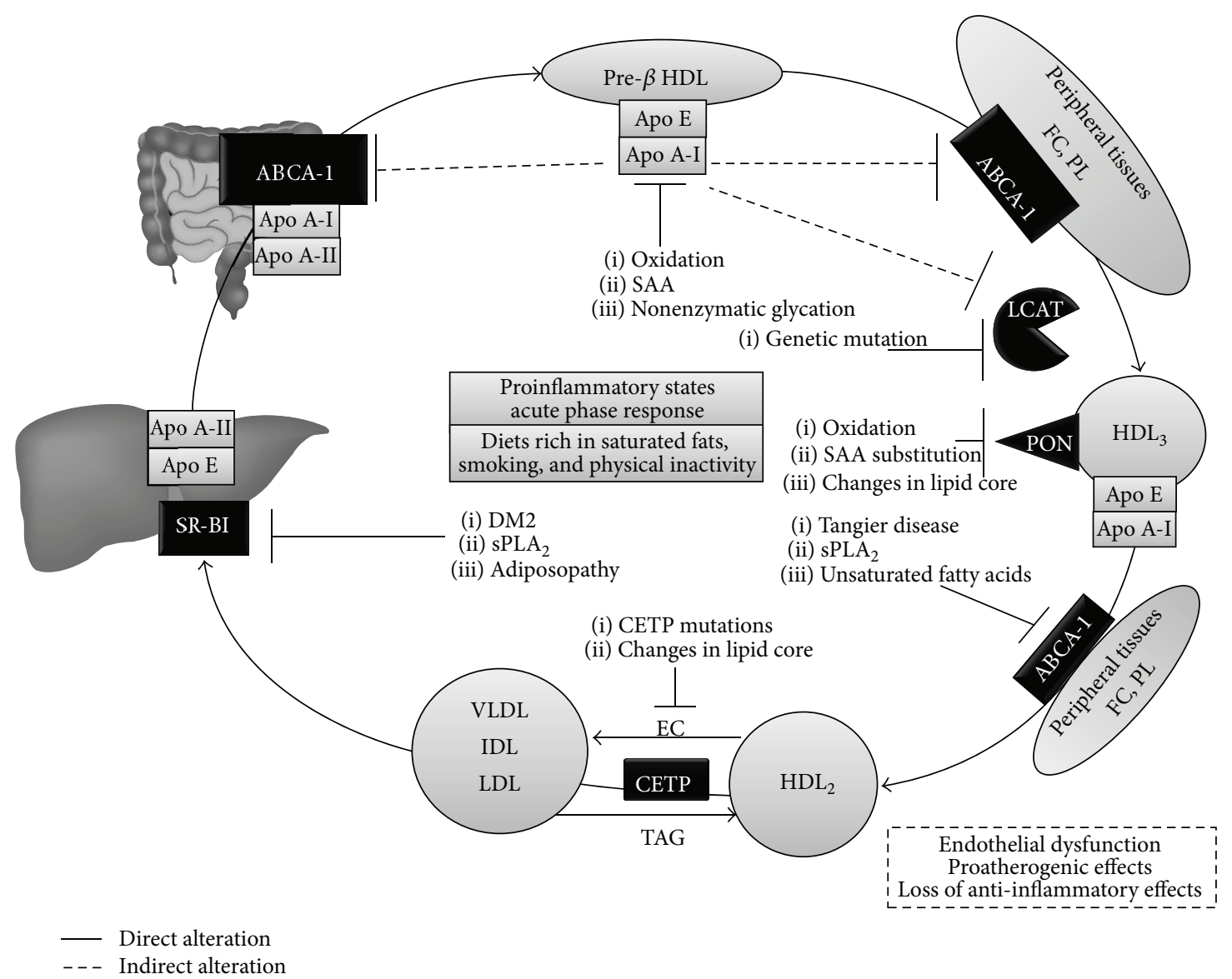

FIGURE 2: Key molecular checkpoints in HDL dysfunction. Genetic mutations, proinflammatory states, and the acute phase response are the main triggers for HDL dysfunction. For details, see the text. FC: free cholesterol; PL: phospholipids; ABCA-1: ATP-binding cassette transporter A-1; LCAT: Lecithin-Cholesterol Acyltransferase; PON: Paraoxonase; CETP: cholesteryl ester transfer protein; HDL: HighDensity Lipoprotein; SR-B1: Scavenger Receptor B1; SAA: Serum Amyloid A; sPLA 2 : Secretory Phospholipase $\mathrm{A}_{2}$.

Furthermore, this heterogeneity in HDL structure is intrinsically related to their diverse functionality, where the specific protein contents-or proteome-of each subfraction are determinant [69]. This enables each subfraction to perform a particular activity, originating subgroups of particles with distinct cardiovascular effects [69]. Thus, alterations in key protein components yield molecules with abnormal functions or attenuated activity, the "dysfunctional HDL" [70]. These disruptions may stem from genetic or chronic proinflammatory environmental cues at various points in HDL metabolism (Figure 2). Indeed, although the acute phase response entails changes in lipid metabolism-aimed at evading injurious stimuli, for example, the lipopolysaccharide of Gram-negative bacteria-with certain atherogenic implications $[71,72]$, these effects are insignificant if the inflammatory stimulus is not prolonged $[73,74]$. In contrast, disorders such as Coronary Artery Disease (CAD) and Type 2 Diabetes Mellitus (DM2) impose an intrinsic chronic inflammatory microenvironment at the endothelial level, triggering protein remodeling of HDL with the subsequent disruption of their antiatherogenic, antioxidant, and anti-inflammatory activities [74]. The molecular mechanisms involved in these phenomena are detailed in the following sections.
4.1. Protein Targets for HDL Dysfunction. Protein structures comprise the majority of components sensitive to modification in HDL (Figure 3(a)). Among these, Apo A-I-an apolipoprotein pivotal for stabilization of nascent HDL, as well as RCT by interacting with LCAT [20]-has amassed the greatest body of evidence [19]. This protein's functionality is disrupted in diseases such as DM2, where lysine residues are targets of nonenzymatic glycation, leading to generation of advanced glycation end-products [75]. This disturbance in protein structure hinders cholesterol efflux from various cells, including macrophages, towards HDL [75], inhibits their ability to interact with LCAT [76], and diminishes their anti-inflammatory activity in smooth muscle [77].

In a proinflammatory environment, Apo A-I becomes a substrate for myeloperoxidase (MPO), a hemoprotein released by macrophages and neutrophils that utilizes hydrogen peroxide $\left(\mathrm{H}_{2} \mathrm{O}_{2}\right)$ and nitric oxide (NO) to catalyze oxidative reactions which yield nitrated reactive species. In turn, these mediators promote oxidative damage, especially on low-density lipoproteins (LDL) $[78,79]$. These events have been demonstrated in vivo, with the detection of MPO in the atheromatous vascular lesions underlying systemic inflammatory states [80]. Likewise, oxidative dysfunction of Apo 


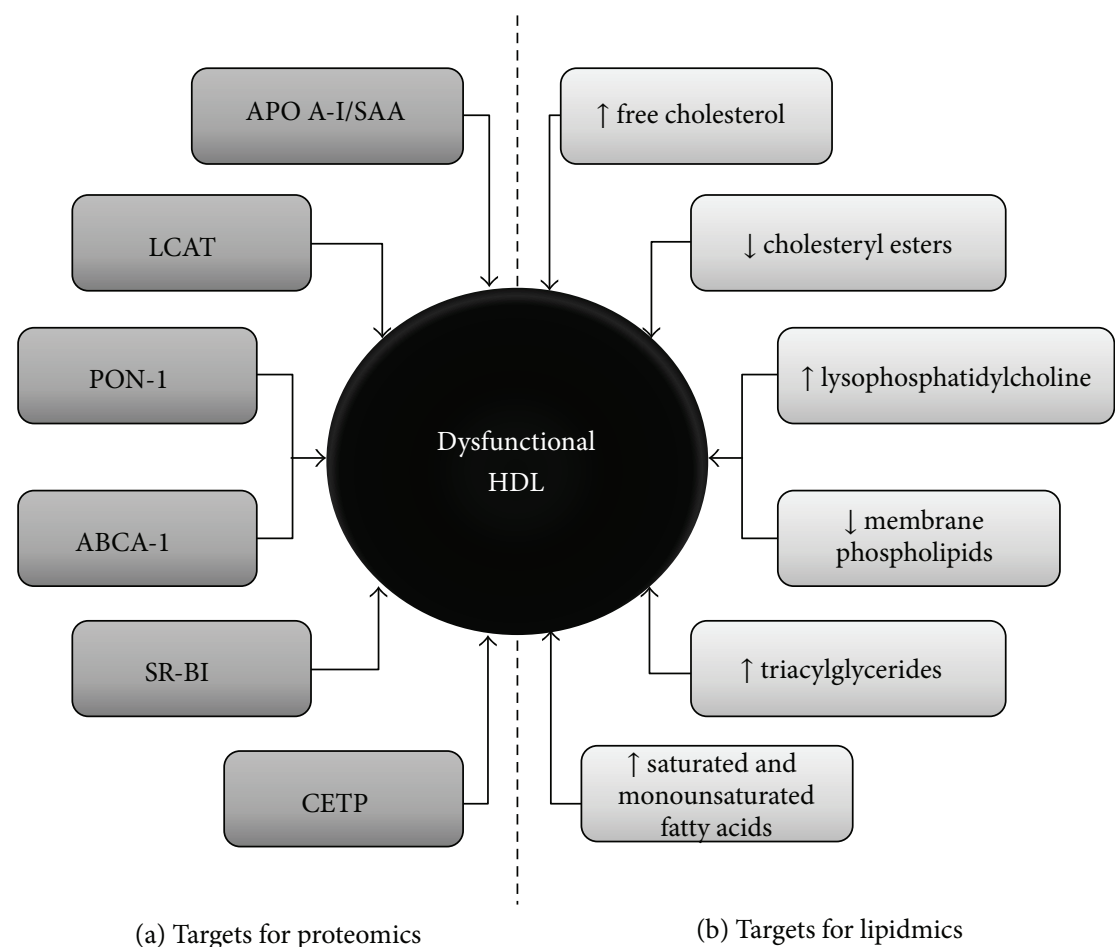

FIgURE 3: Targets susceptible to modification or alteration in HDL. The heterogeneity in HDL components renders these molecules very susceptible to alteration in various aspects. (a) depicts the protein targets, whereas (b) summarizes the lipid targets. These are studied by proteomics and lipidomics, respectively. HDL: High-Density Lipoprotein; SAA: Serum Amyloid A; LCAT: Lecithin-Cholesterol Acyltransferase; PON-1: Paraoxonase; ABCA-1: ATP-binding cassette transporter A-1; SR-B1: Scavenger Receptor B1; CETP: cholesteryl ester Transfer Protein.

A-I interferes with LCAT activation, which is key for RCT and esterification of cholesterol contained in mature HDL [81]. MPO is involved in this mechanism as well: in the presence of elevated concentrations of hypochlorous acid ( $\mathrm{HOCl})$ or hydrogen peroxide, $\mathrm{HDL}_{3}$ become unable to activate LCAT [20]. This particular alteration involves amino acid residues 143-165 of Apo A-I, and particularly Met148, which is most sensitive to oxidizing, becoming methionine sulfoxide (Met[O]) [20, 82, 83]. Oxidation of these residues results in impaired reduction of CE hydroperoxides and PC hydroperoxides, which in physiological conditions would enhance the capture of HDL by hepatocytes [84, 85].

ABCA-1 interacts with Apo A-I by mediating the unidirectional efflux of cholesterol from foamy cells to HDL, preventing excess lipid accumulation in arterial walls [86]. These functions require interaction with completely functional Apo A-I [87]. Various reports describe MPO to act in the subendothelial space by oxidizing Tyr192, Tyr29, Tyr166, and Tyr236 (3-chlorotyrosine and 3-nitrotyrosine) and methionine residues of Apo A-I, disrupting its ability to transport cholesterol with ABCA-1 [88, 89]. Binding of Apo A-I to ABCA-1 and activation of Janus kinase 2 signaling are disrupted by these modifications [90], yielding proatherogenic HDL.

The ABCA-1/Apo A-I complex interacts with enterocytes for cholesterol absorption, HDL lipidation, and its subsequent release to lymphatic vessels [91]. In parallel to these events, HDL complexes also absorb vitamin E, lutein, and zeaxanthin, which are LDL-protecting antioxidant molecules that contribute to formation of nascent $\operatorname{HDL}[92,93]$. ABCA1/Apo A-I activity is also fundamental for formation of nascent HDL (pre- $\beta 1$ fractions) [94], representing a crucial point in the determination of their structure, as marks for further hepatic catabolism, and greater efficiency in RCT $[95,96]$. Inflammation can disrupt all of these interactions, as oxidation of Apo A-I by MPO nullifies its function [97]. In addition, nitration and chlorination of HDL by MPO have been shown to prevent HDL from intervening in endothelial repair [98]. Furthermore, in vitro oxidation of HDL has been observed to promote activation of NF- $\kappa \mathrm{B}$ and expression of vascular adhesion molecules [99] and prevent this molecule from counteracting the vasoactive effects of oxidized LDL [100].

These enzymes are also susceptible to genetic alterations. Heterozygous subjects with defects in LCAT exhibit 36\% lower HDL-C serum concentration, with higher levels of CReactive Protein, and greater intima thickness in the internal carotid arteries [101]. Similarly, in familial LCAT deficiencyan autosomal recessive hereditary disorder [102] — research has highlighted the presence of atherosclerosis in association with early death [103], along with a loss of the antiinflammatory and antioxidant capabilities of HDL [104]. Certain genetic mutations have been described to disrupt ABCA-1, such as in Tangier syndrome, an autosomal recessive disease featuring a marked HDL deficit, lipid accumulation in macrophages, and accelerated atherosclerosis $[105,106]$. 
Genetic alterations of SR-B1-which drives cholesterol from foamy cells in vascular walls to HDL and captures these particles in the liver [107] - also result in significant disturbances in lipid metabolism. SR-BI knockout mice have been found to suffer a greater risk for atherogenesis in spite of elevated HDL-C levels [108], as this yields decreased selective capture of CE in the liver $[109,110]$. This receptor may also intervene in the effects of HDL on endothelial cells, by facilitating NO synthesis, hence promoting endothelial integrity [111]. In addition, dysfunctional HDL appear to contribute to endothelial damage in the setting of DM2. These altered HDL have been observed to diminish SR-BI expression and activity of its Akt-dependent signaling cascades [112], along with anomalous endothelial NO synthase activity [113], leading to endothelial dysfunction.

Both ABCA-1 and SR-BI are modulated by Secretory Phospholipase $\mathrm{A}_{2}\left(\mathrm{sPLA}_{2}\right)$, whose expression is augmented in chronic inflammation [114]. $\mathrm{SPA}_{2}$ participates in various host defense and inflammatory mechanisms [115], belonging to a superfamily of enzymes able to hydrolyze glycerophospholipids at the sn-2 position, producing unsaturated fatty acids such as arachidonic acid, the major substrate for the synthesis of a myriad of messengers, including prostaglandins and leukotrienes [116]. $\mathrm{sPLA}_{2}$ is a paramount mediator within atheromatous plaque, triggering generation of multiple inflammatory intermediaries, oxidizing LDL, and promoting formation of foamy cells [117]. Research in transgenic mice has also shown sPLA 2 to lower not only HDL-C serum levels but also its size and proportion of structural phospholipids [118]. Likewise, sPLA $_{2}$-mediated modification of HDL components has been observed to disrupt the cholesterol efflux associated with decreased expression of ABCA-1, independently of Serum Amyloid A (SAA) concentration [119], possibly through inactivation of LXR transcription factor.

SAA is an acute phase protein synthesized in the liver, which acts in close association with the $\mathrm{HDL}_{3}$ subpopulation [120]. During the acute phase response, circulating SAA displaces Apo A-I and incorporates into the lipoprotein membrane, becoming the major protein component of HDL ( 80\%) [121]. This leads to lower HDL-C concentration by impeding ABCA-1-mediated lipidation of Apo A-I, with reduced formation of nascent HDL [122], along with increased free circulating Apo A-I and TAG, and decreased Paraoxonase-1 (PON-1) levels [123]. These dysfunctional, SAA-rich lipoproteins present a proteoglycan-binding domain-which facilitates its retention in arterial walls-and have lower cholesterol efflux capacity. Indeed, proteomic analyses have demonstrated that HDL's cholesterol efflux capacity is inversely correlated with HDL SAA1 and SAA2 [124].

PON-1-an HDL-bound arylesterase, able to hydrolyze several oxidized or altered lipids, protecting HDL from lipid peroxidation [125] —is another target of modification. Decreased PON-1 activity has been proposed to yield dysfunctional HDL, favoring premature atherosclerosis [126], ostensibly through oxidative stress [127] and production of advanced glycation end-products in hyperglycemic milieus, as seen in DM2 [128], as well as in obese and hyperlipidemic individuals, also characterized by significant inflammation and oxidative stress $[129,130]$. Furthermore, MPO, PON-1, Apo A-I, and HDL can form a ternary complex which further potentiates inflammation, where MPO oxidizes tyrosine residue 71 in PON-1, inhibiting its antioxidant function [131].

Lastly, activity of CETP-responsible for exchange of CE from HDL to TAG-rich lipoproteins (i.e., VLDL, LDL, and IDL), resulting in TAG-rich HDL [132] — can also be downregulated, with beneficial effects, as seen in subjects with the TaqIB polymorphism in the CETP gene, who boast a significantly lower CVR [133]. However, different variants of this gene result in radically distinct phenotypes. In a Japanese population, a G-to-A mutation at the $5^{\prime}$ splice donor site of intron 14 in the CETP gene has been identified to result in hyperalphalipoproteinemia associated with increased CVR $[134,135]$. Although the mechanisms underlying this divergence remain incompletely elucidated, it appears these TAGrich $\mathrm{HDL}$ are unable to promote an adequate efflux of cholesterol from foamy cells [136].

4.2. Lipid Targets for HDL Dysfunction. Although the main targets for modification linked with HDL dysfunction are protein in nature, these may also be affected by changes within its lipid core (Figure 3(b)). Quantitatively, phospholipids (chiefly PC and sphingomyelin) are the main constituents of the HDL lipidome (40-60\%), followed by CE (30$40 \%)$, TAG (5-12\%), and FC (5-10\%) [137]. These components are spatially organized according to their biochemical properties: phospholipids and FC form an outer hydrophilic monolayer which encloses a hydrophobic core rich in $\mathrm{CE}$ and TAG [138]. HDL also carry other lipids with important qualities, including sphingosine-1-phosphate-which is antioxidant and regulated vascular tone and endothelial function [139] — and liposoluble vitamins [140].

Dysfunctional HDL exhibit 25\% less lipids per milligrams of protein, reflecting lower contents of sphingomyelin, phosphatidylinositol, and PC, higher concentration of lysophosphatidylcholine (LPC) and FC, and a substitution of $50 \%$ of CE for TAG [141]. These lipid changes can alter antiatherogenic HDL assets. The reorganization of lipid components caused by upregulated CETP activity-as seen in states of insulin resistance-alters the CE/TAG ratio in $\mathrm{HDL}$, which is fundamental for their antioxidant activity and circulation [142]. Higher TAG contents in the lipid core also impair transfer of CE through SR-BI, hindering RCT [143].

In addition, during acute inflammation, $\mathrm{PLA}_{2}$ subtype IIA is activated, hydrolyzing HDL phospholipids and culminating in accumulation of deleterious oxidized fatty acids [144], which disrupt the secondary and tertiary structure of Apo A-I [145]. In addition, hydrolysis of phospholipids in the superficial monolayer of HDL-for example, by sPLA 2 [146, 147] - leads to redistribution of CE from the core towards the surface monolayer, reducing its fluidity, impairing cholesterol efflux in RCT [148], potentiating release of FC to peripheral tissues [149], and diminishing antioxidant activity [150].

The loss of this protection is particularly important in atherosclerosis, where HDL may prevent LDL oxidation [151], a critical step in the progression of the atheroma, as oxidized LDL is a powerful inducer of monocyte recruitment to the subendothelial space [152]. LDL oxidation also generates 
biologically active phospholipids derived from arachidonic acid, which intervene in chemotaxis and monocyte migration [153], through expression of MCP-1, M-CSF, and IL-18 [154]. In addition, $\mathrm{sPLA}_{2}$ released by activated macrophages modifies the lipid structure of HDL, hydrolyzing phospholipids in their external monolayer [155], yielding a great quantity of unsaturated fatty acids and modified phospholipids, such as LPC [156], a proinflammatory component of atheromatous plaques [157]. LPC has been found to play an active role in atherosclerosis, acting on various cells-monocytes, macrophages, and endothelial and smooth muscle cells-generating oxidative stress, and promoting chemotaxis through expression of adhesion molecules and inflammatory messengers, including IL- $1 \beta$, INF- $\gamma$, and MCP-1 [158]. In subjects with CVD, higher levels of these proinflammatory lipids in HDL have been related to lower cholesterol efflux capacity [159] and attenuated PON-1 activity, inhibiting the antioxidant ability of HDL and turning HDL into proinflammatory agents [160]. Similarly, in DM2, these oxidized lipids generate dysfunctional HDL with altered anti-inflammatory and antioxidant activity [161].

Higher levels of unsaturated fatty acids in HDL can also deteriorate ABCA-1 functionality, inhibiting its expression in cell membranes and augmenting its degradation ratio, with the consequent reduction in cholesterol efflux from vascular spaces to HDL, thus favoring atherogenesis [162]. In addition, unsaturated fatty acids may repress LXR/RXR transcription factors - which promote ABCA-1 synthesis [163] - and activate Protein Kinase $C \delta$, which phosphorylates serine residues in ABCA-1, destabilizing its structure [164].

\subsection{Implications of Environmental Factors on Dysfunctional} $H D L$. Despite the ample diversity of genetic alterations that can lead to HDL deficiency or dysfunction [165], environmental elements also play an important role in these phenomena, as well as various conditions and diseases. Notably, in systemic lupus erythematosus and rheumatoid arthritisboth autoimmune diseases linked to accelerated atherosclerosis-dysfunctional HDL have been observed to be unable to prevent LDL oxidation in vivo $[166,167]$. Likewise, in DM2, persistent hyperglycemia leads to structural changes through glycation of Apo A-I, and other alterations caused by chronic inflammation, including a quantitative reduction in Apo A-I, and increased SAA density [168].

Nascent HDL must undergo a process denominated "lipidation" in order to maintain a proper structure for RCT, which happens mainly in hepatocytes and enterocytes [169]. Nevertheless, adipocytes may also modulate HDL function by transferring cholesterol to these lipoproteins [170], possibly mediated by ABCA-1 and SR-BI in these cells [171]. Indeed, Zhang et al. [170] have demonstrated this premise both in vivo and in vitro, describing mature adipocytes to transfer cholesterol to HDL in a fashion similar to that of macrophages. Disorders such as obesity, insulin resistance, and DM2 feature profound disruptions of adipocyte physiology [172], propitiated by proinflammatory circumstances with high TNF- $\alpha$ levels, which appear to inhibit cholesterol efflux to these cells from HDL, representing a possible contributing factor to low HDL levels in these disorders.
Nutritional factors also influence HDL functionality. In a study by Nicholls et al. [173], subjects on saturated fat-rich diet showed attenuated anti-inflammatory HDL activity 6 hours after intake, whereas individuals on a diet rich in unsaturated fats displayed opposite effects, despite both diets being isocaloric. Likewise, long-term resistance training has been associated with improved redox activity of HDL in young subjects, independently of body weight [174]. In contrast, smoking triggers HDL dysfunction, by hindering functionality of LCAT, CETP, and hepatic lipase, as well as promoting oxidative stress [175]. Therefore, future research should focus on further discerning the impact of these and other environmental factors on HDL, in order to establish pertinent recommendations for the opportune management and prevention of the metabolic disturbances they may promote.

\section{Proteomics and Lipidomics: A Focus on HDL}

HDL participates in an extensive catalogue of intricate pathophysiologic cascades, which demand specialized approaches for their molecular study. Among these stands proteomic research, which employs diverse molecular techniques for detailed description of the structure and function of proteins, in order to discover novel biomarkers and/or therapeutic targets in the diagnosis and treatment of human pathologies and increase our understanding of the underlying biologic processes [176]. On the other hand, lipidomics aim to quantitatively define lipid classes in various biologic systems and characterize their cellular distribution through procedures like mass spectrometry, permitting clarification of the cellular processes in which they intervene [177]. Its application is noteworthy in conditions such as DM2, neurodegenerative disorders, and cystic fibrosis.

In the setting of HDL metabolism, both tools have been utilized for evaluation of functionality, amplifying knowledge of their role in RCT and anti-inflammatory and antioxidant activity. Prominent aspects include protection against LDL oxidation [129], endothelial homeostasis [111], repression of vascular adhesion molecules [178], and inhibition of platelet aggregation [179]. Proteomics and lipidomics may be particularly useful at identifying the molecules associated with HDL that intervene in their inverse relationship with CVR, as quantitative assessment of HDL-C fails to fully explain this premise [180]. These methods may drive a shift in the classical categorization of HDL subfractions, from the established physicochemical classification towards a new model based on their physiologic activity and pathophysiologic roles [181183].

Many techniques are currently utilized; among these, mass spectrometric immunoassay is a high-performance protein analysis method that unites immunoaffinity with the power of mass spectrometry, in order to identify the components of chemical structures [184]. This allows protein isolation and quantification of molecular variants, including changes in primary structure and posttranslational modifications [185]. However, scarce availability of highly purified specific antibodies, elevated costs, problems with immunoaffinity in human samples, and the presence of autoantibodies 
have disfavored this technique [186, 187], paving the way for other methods, such as Selected Reaction Monitoring and Parallel Reaction Monitoring, which allow simultaneous isolation of multiple proteins in complex samples [186]. The former, also called Multiple Reaction Monitoring, is known for its good performance in quantification of various proteins in highly complex and heterogeneous samples, allowing realization of the analysis in a single programmed step [188]. These methods are very efficient for protein quantification, with similar linearity, dynamic range, precision, and repeatability [189]. Nonetheless, Parallel Reaction Monitoring currently appears to be the best method, by virtue of its relative simplicity and greater specificity-due to its use of isotope marking [189] - and its reproducibility is apt for great-scale widespread application [190].

These methods suffer certain limitations. For example, they require knowledge of the molecular weight of the peptide analyte and its fragmentation pattern; thus, sensitivity may be diminished in samples with high protein content without a preliminary analysis [191]. In this case, complementary procedures that reduce this abundance of protein may aid in preserving sensitivity. These include multiplexed immunoassay panels (Multianalyte Profiling), which complements Multiple Reaction Monitoring, assuring adequate sensitivity for quantitative protein analysis [191].

5.1. Contributions of Proteomics and Lipidomics to HDL Research. Although initial studies exploiting these techniques in this setting were centered on proteins already known to be associated with HDL and lipid metabolism [192], further research managed to identify several other proteins previously unknown to be related to HDL, including complement factors and other immune and coagulation intermediaries [193]. Likewise, differing protein expression patterns were described for $\mathrm{HDL}_{2}$ and $\mathrm{HDL}_{3}$, raising interest in the functional roles for each subfraction [192].

These tools have allowed identification of a wide array of proteins involved in inflammation, such as components of the complement system (C3, C4, and C5), vitronectin, clusterin (Apo J), and HDL-associated endopeptidases [66]. The complement system has been observed to directly participate in inflammation in atheromas [194], regulated by vitronectin and clusterin [195]. Likewise, in vitro assays have shown HDL can prevent organization of the membrane attack complex $[196,197]$ and share a negative correlation with C5b-9 levels [198], promoting complement inhibition.

HDL also appears to act as platforms for organization and mobilization of immune responses. Extracellular vesicles in close association with these lipoproteins have been described to contain a diversity of immunity-related microRNA molecules and complement-activating proteins [199201]. More selectively, HDLs are also anchors for the organization the trypanosome lytic factor, a macromolecular complex containing Apo L1 and haptoglobin-related protein, highly lytic for Trypanosoma brucei [202]. This complex binds to HDL through an 18-amino acid signal peptide in its $\mathrm{N}$-terminal region, interacting with lipids in the lipoprotein's monolayer [203]. This complex mediates hemoglobin binding and endocytosis of the parasite, facilitating its lysis and impeding progression of this infection [204].

Furthermore, HDLs have been proved to induce a shift in macrophage phenotype, decreasing expression of proinflammatory mediators such as INF- $\gamma$, iNOS, IL- 6 , and TNF- $\alpha$ and potentiating the expression of IL- 4 and markers typical of anti-inflammatory M2 macrophages, including Arg-1, Receptor, CD163, Fizz-1, and YM-1, through JAK/STAT6dependant cascades [205]. In contrast, individuals with subclinical atherosclerosis exhibit dysfunctional HDL with lower PON-3 activity, reducing their antioxidant capacity in the atherosclerotic plaque [206]. Furthermore, HDLs of individuals with DM2 or established CVD carry proteins such as ENRAGE, MPO, and plasminogen activator inhibitor-1, promoting atherosclerosis [191].

Finally, the precision of proteomics and lipidomics has allowed characterization of the local distribution of various kinds of molecules within the atherosclerotic plaque [207, 208], allowing further molecular differentiation between stable and unstable plaques, extending our comprehension on the processes leading to plaque rupture [209, 210]. Stable plaques display higher levels of superoxide dismutase 2 and fibrinogen fragment D-with antioxidant effects [211] - and participate in smooth muscle contraction [212], respectively, and lower expression of glutathione S-transferase, Rho GDPdissociation inhibitor 1, HSP20, and HSP27, which defend against electrophile reactants in vessel walls [213], regulate smooth muscle tone [214], and modulate cell growth and motility [215], respectively. This evidence posits a role for HDL in innate immunity and novel mechanisms in chronic inflammation and atherosclerosis $[208,216]$.

5.2. Proteomics, Lipidomics, Cardiovascular Risk, and Clinical Applications. Decades ago, $\mathrm{HDL}_{2}$ and $\mathrm{HDL}_{3}$ subfractions were first obtained through ultracentrifugation, representing the gold standard method for this objective [217]. These subfractions have been studied regarding their ability to predict CVR and whether assessment of their biologic behavior is comparable to evaluation of total HDL-C concentration. In multiple studies, $\mathrm{HDL}_{3}$ have been inversely related to CVR - more strongly than $\mathrm{HDL}_{2}[218,219]$ —even in patients with established CVD [220]. Because these subfractions are susceptible to isolation and quantification based on their physicochemical properties, proteomics may propel the proposal of new, more sensitive CVR markers, as well as facilitating assessment of their reproducibility in the clinical setting [221] (Table 3).

These techniques have revealed qualitative alterations in HDL in subjects with CVD [66, 222-224], DM2 [225], chronic kidney disease [226-228], and rheumatoid arthritis [229] in comparison to healthy populations, often without significantly lower HDL-C concentrations [66, 222]. Gene ontology has allowed exploration of these changes. In these scenarios, proinflammatory HDL-associated proteins are upregulated-for example, SAA2, C5, histone H1, and fibrinogen $\beta$-chain binding to HDL-whereas lipid metabolismrelated HDL-associated proteins are downregulated, including Apo C-I, Apo C-II, Apo E, LCAT, and PLTP [223, 230]. Apo A-I is also vulnerable to numerous modifications; in 
TABLE 3: Contributions of proteomics and lipidomics to cardiovascular risk estimation.

\begin{tabular}{|c|c|c|}
\hline Author [reference] & Methodology & Results \\
\hline Vaisar et al. [66] & $\begin{array}{l}7 \text { males with established CVD were } \\
\text { compared with } 6 \text { healthy, age-matched } \\
\text { subjects, whose HDL-C, } \mathrm{HDL}_{3} \text {, and } \\
\text { HDL-associated proteins were studied. }\end{array}$ & $\begin{array}{l}\text { No significant differences in HDL-C concentration were found } \\
\text { between groups ( } 40 \pm 11 \mathrm{mg} / \mathrm{dL} \text { versus } 45 \pm 12 \mathrm{mg} / \mathrm{dL} \text {, resp.). In } \\
\text { individuals with CVD, the proteins most commonly found } \\
\text { associated with } \mathrm{HDL}_{3} \text { were Apo C-IV, PON-1, C3, Apo A-IV, and } \\
\text { Apo E. } \mathrm{HDL}_{3} \text { of control subjects were found to have increased } \\
\text { levels of clusterin and vitronectin. }\end{array}$ \\
\hline Tan et al. [222] & $\begin{array}{l}40 \text { subjects with established CVD were } \\
\text { compared to } 40 \text { healthy subjects, who had } \\
\text { their } \mathrm{HDL}_{3} \text { and } \mathrm{HDL}_{2} \text { studied } \\
\text { quantitatively and qualitatively. }\end{array}$ & $\begin{array}{l}\text { No significant differences in HDL-C concentration were found } \\
\text { between groups. However, in subjects with CVD, HDL }{ }_{3} \text { were } \\
\text { found to be rich in Apo E, Apo A-I, Apo A-IV, Apo L1, Serum } \\
\text { Amyloid P component, PON-1, } \alpha \text {-1B glycoprotein, and vitamin } \\
\text { D-binding protein, along with low Rab levels. Likewise, } \mathrm{HDL}_{2} \\
\text { were found to have low levels of Apo A1, Apo E, PON-1, Apo L1, } \\
\text { haptoglobin, serotransferrin, Rab7, and complement factor B, } \\
\text { along with increased Serum Amyloid P component, } \alpha-1 \\
\text { antitrypsin, and acid ceramidase. }\end{array}$ \\
\hline
\end{tabular}

12 HDL-associated proteins differed significantly between subjects with chronic heart disease and healthy individuals, most of which participate in lipid metabolism. Gene ontology analysis revealed

Case-control study comprising 10 males with chronic heart disease versus 10 Yan et al. [223] healthy subjects matched by age, Body their HDL composition studied for comparison. proteins involved in inflammation and other immune responses

(SAA, C5, histone H1, and fibrinogen beta chain) to be differentially upregulated, whereas proteins involved in lipid metabolism (Apo C-I, Apo C-II, and fatty acid-binding protein) were differentially downregulated. Further ELISA analysis supported these findings, confirming higher SAA and lower Apo $\mathrm{C}$-I in subjects with chronic heart disease versus healthy subjects $(126.5 \pm 67.3 \mu \mathrm{g} / \mathrm{mg}$ versus $68.7 \pm 12.4 \mu \mathrm{g} / \mathrm{mg}, p=0.024$; and $68.8 \pm$ $14.4 \mu \mathrm{g} / \mathrm{mg}$ versus $81.1 \pm 10.6 \mu \mathrm{g} / \mathrm{mg}, p=0.040$, resp.).

The apolipoproteins of 79 patients undergoing carotid endarterectomy (due

Lepedda et al. [224] to stenosis $>70 \%$ ) were isolated and compared with those from 57 normolipemic subjects.

HDL was isolated from end-stage renal disease patients on maintenance

Holzer et al. [226] hemodialysis $(n=27)$ and healthy subjects $(n=19)$; proteomic techniques allowed identification of HDL-associated proteins in both groups. Apo A-I, Apo C-II, Apo C-III, Apo E, Apo D, and SAA were found to be associated with HDL. Only SAA was found to display a significant differential distribution, being more abundant in the group undergoing carotid endarterectomy $(p=0.045)$. SAA may be a CVR marker reflecting HDL quality.

Patients on hemodialysis had lower levels of HDL-C $(61 \mathrm{mg} / \mathrm{dL}$ versus $43 \mathrm{mg} / \mathrm{dL}, p<0.01$ ). $35 \mathrm{HDL}$-associated proteins were identified, most abundantly Apo A-I and Apo A-II. SAA was found only in the HDL of patients on hemodialysis. 9 proteins were found to be significantly altered in this group, including SAA. In addition, HDL of this group displayed lower proportions of phospholipids and higher proportions of LPC. Individuals on hemodialysis showed significantly lower HDL-C A quantitative proteomic analysis was Mangé et al. [227] realized in 23 patients on hemodialysis and 23 age-matched control subjects. and serotransferrin levels, along with increased expression of Apo C-II and Apo C-III (with greater Apo C-II/Apo C-III ratio), which may act as markers of HDL maturity.

Gene ontology functional analysis showed that in the group with end-stage renal disease, HDL-associated proteins involved in lipid metabolism were disrupted (including Apo A-I, Apo E, Apo A-IV, PON-1, LCAT, and PLTP). Instead, their HDL were found to be rich in surfactant protein B, Apo C-II, SAA, and $\alpha$-1-microglobulin, representing a possible explanation for the increased inflammation and cardiovascular mortality seen in uremia.

Patients with DM2 plus CVD displayed significantly lower levels of HDL-associated Apo A-I when compared to subjects with DM2 only ( $84 \pm 39$ versus $90 \pm 40 ; p<0.05$ ). Molecular methods allowed determination of a relative oxidation ratio of the M148 residue in Apo A-I. This ratio was significantly higher in the groups with DM2 and CVD $(0.236 \pm 0.084)$ and DM2 only $(0.127 \pm 0.037)$, in comparison to the control group $(0.087 \pm 0.02)$; and $p<0.05$. 
TABLE 3: Continued.

\begin{tabular}{|c|c|c|}
\hline Author [reference] & Methodology & Results \\
\hline Jensen et al. [232] & $\begin{array}{l}\text { 173,230 subjects from the Nurses' Health } \\
\text { Study (NHS) and the Health Professionals } \\
\text { Follow-Up Study (HPFS), who had their } \\
\text { levels of Apo C-III-associated and } \\
\text { non-ApoC-III-associated HDL quantified } \\
\text { and evaluated in regard to CVR. }\end{array}$ & $\begin{array}{l}\text { HDL-C concentration was negatively correlated with CVR in both } \\
\text { studies (IRR: } 0.78 \text {; } 95 \% \text { IC: } 0.63-0.96, p=0.02 \text { ). Nevertheless, } \\
\text { increased levels of non-Apo C-III-associated HDL were negatively } \\
\text { associated with CVR (IRR: } 0.66 \text {; 95\% IC: } 0.53-0.83, p=0.0001 \text { ), } \\
\text { whereas increased levels of Apo C-III-associated HDL were } \\
\text { positively associated with CVR (IRR: } 1.18 ; 95 \% \text { IC: } 1.03-1.34 \text {, } \\
p=0.001 \text { ). }\end{array}$ \\
\hline Ståhlman et al. [225] & $\begin{array}{l}\text { Mass spectrometry was used to } \\
\text { characterize the lipidome of } 3 \text { groups of } \\
\text { women from the DIWA study: (a) control } \\
\text { group; (b) DM2 + insulin resistance + } \\
\text { dyslipidemia; (c) DM2 + insulin } \\
\text { resistance + normolipemia. }\end{array}$ & $\begin{array}{l}\text { Smaller HDL particles were found in the dyslipidemic group, with } \\
\text { increased LPC (13\%) palmitate-rich triacylglycerols and } \\
\text { diacylglycerols ( } 77 \%) \text { possibly reflecting enhanced CETP activity. } \\
\text { The subjects also displayed a high Apo A-I/plasmalogen ratio } \\
\text { compatible with oxidative stress seen in DM2. }\end{array}$ \\
\hline Kostara et al. [244] & $\begin{array}{l}\text { Case-control study with } 60 \text { subjects with } \\
\text { normal coronary arteries and } 99 \text { patients } \\
\text { with established CVD grouped by } \\
\text { severity of coronary artery stenosis (mild, } \\
\text { moderate, and severe). Lipidomic analysis } \\
\text { assessed patterns in the constitution of } \\
\text { HDL in each group. }\end{array}$ & $\begin{array}{l}\text { HDL-C was significantly lower in the mild disease group versus } \\
\text { severe disease group ( } 43.6 \pm 10.9 \mathrm{mg} / \mathrm{dL} \text { versus } 38.4 \pm 6.8 \mathrm{mg} / \mathrm{dL}) \text {. } \\
\text { Subjects with CVD had higher proportions of saturated fatty acids, } \\
\text { phospholipids, triacylglycerides, and cholesteryl esters in HDL in } \\
\text { comparison to controls, along with lower proportions of } \\
\text { sphingomyelin and phosphatidylcholine. Likewise, subjects with } \\
\text { mild disease had greater proportions of phosphatidylcholine, } \\
\text { unsaturated fatty acids, omega-3 fatty acids, and sphingomyelin } \\
\text { than subjects with severe disease. }\end{array}$ \\
\hline Yetukuri et al. [240] & $\begin{array}{l}\text { Subjects from the Fibrate Intervention and } \\
\text { Event Lowering in Diabetes (FIELD) } \\
\text { substudy, whose changes in proteome } \\
\text { and lipidome were evaluated after } \\
\text { receiving (a) fenofibrate } 200 \mathrm{mg} \text { daily or } \\
\text { (b) placebo. }\end{array}$ & $\begin{array}{l}\text { No difference was found in HDL-C levels between groups } \\
(p>0.05) \text {. HDL from the fenofibrate group had lower LPC and } \\
\text { higher sphingomyelin and Apo A-II. }\end{array}$ \\
\hline
\end{tabular}

particular, oxidation of residue M148 has been extensively documented in CVD and DM2 [231]. Expression of Apo E in $\mathrm{HDL}_{3}$ also appears to be increased in individuals with CVD [66], and HDL-bound Apo C-III has been related to higher CVR [232]. Nonetheless, SAA may yield greater clinical utility. This protein has been described to be better predictor of clinical outcomes in non-ST-segment elevation acute coronary syndrome in comparison to C-Reactive Protein [233]; and the quantity of HDL-bound SAA has been correlated with levels of inflammatory markers [230].

Many other proteins may bind to HDL, most likely by hepatic remodeling or interactions in peripheral tissues, with significant impact in atherogenesis [234, 235]. Future studies should aim to more thoroughly characterize the role of these HDL-associated proteins in the functionality of this lipoprotein, their clinical utility, and their potential as therapeutic targets. Promising candidates for this research include the fatty acid-binding protein, hemoglobin, HLAA43 [223], rab7b, $\alpha$-1-antitrypsin, Serum Amyloid P component [222], $\alpha 1$-acid glycoprotein 1, zinc- $\alpha 2$-glycoprotein, surfactant-associated protein B (SP-B), c-src, complement factor D [230], complement factor B, complement components 4B and C1s, vitronectin, and prothrombin [234].

Proteomics also allows continuous observation of structural and functional changes in HDL in response to pharmacological intervention, as executed by Green et al. [236], who found combined statin/niacin therapy to improve $\mathrm{HDL}_{3}$ composition in patients with established CVD, with a decrease in Apo E contents $(p=0.02)$ and an increase in PLTP concentration $(p=0.02)$ after a year on treatment, thus representing a structural shift in this subfraction towards an architecture resembling that found in healthy subjects. Another interesting aspect in this field is the prediction of complications during treatment. The expression of arachidonate 5-lipoxygenase-activating protein-whose increased activity in muscle is a hallmark of simvastatin use-may be monitored through proteomics, allowing titration of doses in order to avoid statin-associated toxicity [237]. Likewise, proteomics may help decipher the causes of failure of certain therapeutic trials, as seen in the Fibrate Intervention and Event Lowering in Diabetes (FIELD) substudy [238]. In this report, no benefit was ascertained for $200 \mathrm{mg}$ fenofibrate OD versus placebo regarding CVR [238]. Ulterior analysis showed subjects in this regimen to have higher Apo A-II levels and lower PON and PTLP activity in HDL, as well as compositional changes in lipid conglomerates, such as increased LPC and decreased sphingomyelin, favoring LCAT disruption [239] and slowing maturation of HDL [240]. This kind of treatment evaluation may also be useful in surgical scenarios, as in the case of subjects who have undergone closure of patent foramen ovale, where an increase in cholesterol efflux and a decrease in lipid oxidation can be detected after surgery, with cardiovascular benefits [241]. Similarly, patients with $>70 \%$ stenosis of carotid arteries have 
been shown to have higher SAA proportions in HDL when compared to normolipemic subjects $(p=0.003)$, confirmed by western blot analyses [224].

Lastly, molecular HDL analysis not only facilitates therapeutic response analysis but may also assist in application of therapeutic measures involving ligand-receptor interactions. Apo A1 expression has been experimentally upregulated in HDL by exploiting an HDL-conjugated chimeric IL-15 fusion protein and Sushi domains in this interleukin, resulting in stimulation of T lymphocytes and NK cells [242]. Similarly, anchoring Apo A1 to IFN- $\alpha$ has been reported to potentiate cytotoxic T lymphocytes and attenuate side effects of IFN$\alpha$ monotherapy [243]. These innovative findings profile proteomics as an important tool in the study of HDL as vehicles for immunomodulation.

On the other hand, research in lipidomics has found significant associations between HDL lipid composition and cardiometabolic disease. Lower phospholipid proportions in dysfunctional HDL have been reported to impair cholesterol efflux [226], even independently of SAA concentration [114]. Lipidomics has also found differences in HDL constitution depending on severity of CVD. Concentrations of PC, unsaturated fatty acids, omega-3 fatty acids, and sphingomyelin appear to be significantly higher in earlier stages of CVD than in more severe cases [244]. Other changes in lipid composition of HDL have been found in CVD and DM2, including higher TAG, saturated fatty acids, diallyl fatty acids, linoleic acid [245], LPC, palmitate-rich triacylglycerols, and diacylglycerols [225], as well as increased products of lipid peroxidation such as 5-HETE, 12-HETE, 15-HETE, 13HODE, and 9-HODE [246].

\section{Conclusions}

HDL is one of the most biologically variable molecules, with a great heterogeneity dictated by specific groupings of proteins or lipids, suggesting the existence of various subfractions with distinct functional profiles. Although their main role involves prevention of cholesterol accumulation in peripheral tissues, their participation in beneficial processes is hardly limited to this aspect. Multiple pathologic conditions trigger structural and functional alterations in $\mathrm{HDL}$, becoming proinflammatory molecules unable to maintain endothelial homeostasis, thus becoming "dysfunctional HDL." To elucidate this dysfunctionality, detailed research at a molecular level is required on the various components associated with these lipoproteins, uncovering new therapeutic alternatives regarding progression of atherosclerosis. To this end, proteomics and lipidomics appear to be the most promising methods in the exploration of the physiologic, pathologic, and potentially therapeutic roles of HDL.

\section{Abbreviations}

ABCA-1: ATP-binding cassette transporter A-1

Apo A-I: Apolipoprotein A-I

CAD: Coronary artery disease

CE: Cholesteryl ester

CETP: Cholesteryl ester transfer protein
CVD: Cardiovascular disease

CVR: Cardiovascular risk

DM2: Type 2 diabetes mellitus

FC: $\quad$ Free cholesterol

HDL: High-Density Lipoprotein

IDL: Intermediate-Density Lipoprotein

LCAT: Lecithin-Cholesterol Acyltransferase

LDL: Low-Density Lipoprotein

LPC: Lysophosphatidylcholine

MPO: Myeloperoxidase

PC: Phosphatidylcholine

$\mathrm{PLA}_{2}$ : Phospholipase $\mathrm{A}_{2}$

PON-1: Paraoxonase-1

RCT: Reverse cholesterol transport

SAA: Serum Amyloid A

SNP: Single-nucleotide polymorphism

SR-BI: Scavenger Receptor class B type I

sPLA $_{2}$ : Secretory Phospholipase $\mathrm{A}_{2}$

TAG: Triacylglycerides

VLDL: Very low-density lipoprotein.

\section{Conflict of Interests}

The authors confirm that this paper's content has no conflict of interests.

\section{Acknowledgments}

This work was supported by Research Grant no. CC-0437-1021-09-10 from the Technological, Humanistic, and Scientific Development Council, University of Zulia, and Research Grant no. FZ-0058-2007 from Fundacite-Zulia.

\section{References}

[1] WHO, "The top ten causes of death. Fact sheet 310," 2011, http://www.who.int/mediacentre/factsheets/fs310_2008.pdf.

[2] C. J. O’Donell and R. Elosua, "CVR factors. Insights from Framingham Heart Study," Revista Española de Cardiología, vol. 61, no. 3, pp. 299-310, 2008.

[3] J. Millán, X. Pintó, A. Muñoz et al., "Lipoprotein ratios: physiological significance and clinical usefulness in cardiovascular prevention," Vascular Health and Risk Management, vol. 5, pp. 757-765, 2009.

[4] World Health Organization, Report on the Global Tobacco Epidemic 2011: Warning about the Dangers of Tobacco, World Health Organization, Geneva, Switzerland, 2011, http://www.who.int/ tobacco/global_report/2011/en/.

[5] K. K. Ray, J. J. P. Kastelein, S. M. Boekholdt et al., "The ACC/AHA 2013 guideline on the treatment of blood cholesterol to reduce atherosclerotic cardiovascular disease risk in adults: the good the bad and the uncertain: a comparison with ESC/ EAS guidelines for the management of dyslipidaemias 2011," European Heart Journal, vol. 35, no. 15, pp. 960-968, 2014.

[6] P. Barter, A. M. Gotto, J. C. LaRosa et al., "HDL cholesterol, very low levels of LDL cholesterol, and cardiovascular events," The New England Journal of Medicine, vol. 357, no. 13, pp. 1301-1310, 2007.

[7] A. Kontush and M. J. Chapman, "Antiatherogenic small, dense HDL_-guardian angel of the arterial wall?" Nature Clinical 
Practice Cardiovascular Medicine, vol. 3, no. 3, pp. 144-153, 2006.

[8] S. Lund-Katz and M. C. Phillips, "High density lipoprotein structure-function and role in reverse cholesterol transport," Sub-Cellular Biochemistry, vol. 51, pp. 183-227, 2010.

[9] L. Camont, M. J. Chapman, and A. Kontush, "Biological activities of HDL subpopulations and their relevance to cardiovascular disease," Trends in Molecular Medicine, vol. 17, no. 10, pp. 594-603, 2011.

[10] W. P. Castelli, J. T. Doyle, T. Gordon et al., "HDL cholesterol and other lipids in coronary heart disease. The cooperative lipoprotein phenotyping study," Circulation, vol. 55, no. 5, pp. 767772, 1977.

[11] T. Gordon, W. P. Castelli, M. C. Hjortland, W. B. Kannel, and T. R. Dawber, "High density lipoprotein as a protective factor against coronary heart disease: the Framingham study," The American Journal of Medicine, vol. 62, no. 5, pp. 707-714, 1977.

[12] P. W. F. Wilson, R. D. Abbott, and W. P. Castelli, "High density lipoprotein cholesterol and mortality. The Framingham Heart Study," Arteriosclerosis, vol. 8, no. 6, pp. 737-741, 1988.

[13] J. A. Kuivenhoven, H. Pritchard, J. Hill, J. Frohlich, G. Assmann, and J. Kastelein, "The molecular pathology of lecithin: cholesterol acyltransferase (LCAT) deficiency syndromes," Journal of Lipid Research, vol. 38, no. 2, pp. 191-205, 1997.

[14] G. Franceschini, C. R. Sirtori, A. Capurso, K. H. Weisgraber, and R. W. Mahley, "A-I Milano apoprotein: decreased high density lipoprotein cholesterol levels with significant lipoprotein modifications and without clinical atherosclerosis in an Italian family," The Journal of Clinical Investigation, vol. 66, no. 5, pp. 892-900, 1980.

[15] E. Bruckert, A. von Eckardstein, H. Funke et al., "The replacement of arginine by cysteine at residue 151 in apolipoprotein A-I produces a phenotype similar to that of apolipoprotein A-I Milano," Atherosclerosis, vol. 128, no. 1, pp. 121-128, 1997.

[16] P. J. Barter, M. Caulfield, M. Eriksson et al., "Effects of torcetrapib in patients at high risk for coronary events," The New England Journal of Medicine, vol. 357, no. 21, pp. 2109-2122, 2007.

[17] E. Eren, N. Yilmaz, and O. Aydin, "High density lipoprotein and it's dysfunction," Open Biochemistry Journal, vol. 6, pp. 78-93, 2012.

[18] G. Schonfeld and B. Pfleger, "The structure of human high density lipoprotein and the levels of apolipoprotein A-I in plasma as determined by radioimmunoassay," The Journal of Clinical Investigation, vol. 54, no. 2, pp. 236-246, 1974.

[19] L. S. Kumpula, J. M. Kumpula, M.-R. Taskinen, M. Jauhiainen, K. Kaski, and M. R. Ala-Korpela, "Reconsideration of hydrophobic lipid distributions in lipoprotein particles," Chemistry and Physics of Lipids, vol. 155, no. 1, pp. 57-62, 2008.

[20] M. G. Sorci-Thomas, S. Bhat, and M. J. Thomas, "Activation of lecithin: cholesterol acyltransferase by HDL ApoA-I central helices," Clinical Lipidology, vol. 4, no. 1, pp. 113-124, 2009.

[21] L. Zhang, F. Yan, S. Zhang et al., "Structural basis of transfer between lipoproteins by cholesteryl ester transfer protein," Nature Chemical Biology, vol. 8, no. 4, pp. 342-349, 2012.

[22] H.-O. Mowri, J. R. Patsch, A. Ritsch, B. Foger, S. Brown, and W. Patsch, "High density lipoproteins with differing apolipoproteins: relationships to postprandial lipemia, cholesteryl ester transfer protein, and activities of lipoprotein lipase, hepatic lipase, and lecithin: cholesterol acyltransferase," Journal of Lipid Research, vol. 35, no. 2, pp. 291-299, 1994.
[23] A. Jonas, "Lipoprotein structure," in Biochemistry of Lipids, Lipoproteins and Membranes, Elsevier, Amsterdam, The Netherlands, 4th edition, 2002.

[24] H. B. Brewer Jr. and S. Santamarina-Fojo, "Clinical significance of high-density lipoproteins and the development of atherosclerosis: focus on the role of the adenosine triphosphatebinding cassette protein A1 transporter," The American Journal of Cardiology, vol. 92, no. 4, pp. 0K-16K, 2003.

[25] S. Kunnen and M. Van Eck, "Lecithin: cholesterol acyltransferase: old friend or foe in atherosclerosis?" Journal of Lipid Research, vol. 53, no. 9, pp. 1783-1799, 2012.

[26] K.-A. Rye, C. A. Bursill, G. Lambert, F. Tabet, and P. J. Barter, "The metabolism and anti-atherogenic properties of HDL," Journal of Lipid Research, vol. 50, supplement, pp. S195-S200, 2009.

[27] D. Bailey, I. Ruel, A. Hafiane et al., "Analysis of lipid transfer activity between model nascent HDL particles and plasma lipoproteins: implications for current concepts of nascent HDL maturation and genesis," Journal of Lipid Research, vol. 51, no. 4, pp. 785-797, 2010.

[28] M. Jauhiainen, J. Metso, R. Pahlman, S. Blomqvist, A. Van Tol, and C. Ehnholm, "Human plasma phospholipid transfer protein causes high density lipoprotein conversion," Journal of Biological Chemistry, vol. 268, no. 6, pp. 4032-4036, 1993.

[29] S. Lusa, M. Jauhiainen, J. Metso, P. Somerharju, and C. Ehnholm, "The mechanism of human plasma phospholipid transfer protein-induced enlargement of high-density lipoprotein particles: evidence for particle fusion," Biochemical Journal, vol. 313, no. 1, pp. 275-282, 1996.

[30] G. Wolfbauer, J. J. Albers, and J. F. Oram, "Phospholipid transfer protein enhances removal of cellular cholesterol and phospholipids by high-density lipoprotein apolipoproteins," Biochimica et Biophysica Acta, vol. 1439, no. 1, pp. 65-76, 1999.

[31] J. Huuskonen, V. M. Olkkonen, C. Ehnholm, J. Metso, I. Julkunen, and M. Jauhiainen, "Phospholipid transfer is a prerequisite for PLTP-mediated HDL conversion," Biochemistry, vol. 39, no. 51, pp. 16092-16098, 2000.

[32] J. F. Oram, G. Wolfbauer, C. Tang, W. S. Davidson, and J. J. Albers, "An amphipathic helical region of the N-terminal barrel of phospholipid transfer protein is critical for ABCA1dependent cholesterol efflux," The Journal of Biological Chemistry, vol. 283, no. 17, pp. 11541-11549, 2008.

[33] C. J. Fielding and P. E. Fielding, "Molecular physiology of reverse cholesterol transport," Journal of Lipid Research, vol. 36, no. 2, pp. 211-228, 1995.

[34] M. J. Chapman, W. Le Goff, M. Guerin, and A. Kontush, "Cholesteryl ester transfer protein: at the heart of the action of lipid-modulating therapy with statins, fibrates, niacin, and cholesteryl ester transfer protein inhibitors," European Heart Journal, vol. 31, no. 2, pp. 149-164, 2010.

[35] H. Mabuchi, A. Nohara, and A. Inazu, "Cholesteryl ester transfer protein (CETP) deficiency and CETP inhibitors," Molecules and Cells, vol. 37, no. 11, pp. 777-784, 2014.

[36] T. Yasuda, T. Ishida, and D. J. Rader, "Update on the role of endothelial lipase in high-density lipoprotein metabolism, reverse cholesterol transport, and atherosclerosis," Circulation Journal, vol. 74, no. 11, pp. 2263-2270, 2010.

[37] B. Trigatti, S. Covey, and A. Rizvi, "Scavenger receptor class B type I in high-density lipoprotein metabolism, atherosclerosis and heart disease: Lessons from gene-targeted mice," Biochemical Society Transactions, vol. 32, part 1, pp. 116-120, 2004. 
[38] G. F. Lewis and D. J. Rader, "New insights into the regulation of HDL metabolism and reverse cholesterol transport," Circulation Research, vol. 96, no. 12, pp. 1221-1232, 2005.

[39] D. L. Silver, N. Wang, X. Xiao, and A. R. Tall, "High density lipoprotein (HDL) particle uptake mediated by scavenger receptor class $B$ type 1 results in selective sorting of $\mathrm{HDL}$ cholesterol from protein and polarized cholesterol secretion," Journal of Biological Chemistry, vol. 276, no. 27, pp. 25287-25293, 2001.

[40] T. A. Pagler, S. Rhode, A. Neuhofer et al., "SR-BI-mediated high density lipoprotein (HDL) endocytosis leads to HDL resecretion facilitating cholesterol efflux," The Journal of Biological Chemistry, vol. 281, no. 16, pp. 11193-11204, 2006.

[41] R. Alam, F. M. Yatsu, L. Tsui, and S. Alam, "Receptor-mediated uptake and 'retroendocytosis' of high-density lipoproteins by cholesterol-loaded human monocyte-derived macrophages: possible role in enhancing reverse cholesterol transport," Biochimica et Biophysica Acta, vol. 1004, no. 3, pp. 292-299, 1989.

[42] S. Rhode, A. Breuer, J. Hesse et al., "Visualization of the uptake of individual HDL particles in living cells via the scavenger receptor class B type I," Cell Biochemistry and Biophysics, vol. 41, no. 3, pp. 343-356, 2004.

[43] B. Sun, E. R. M. Eckhardt, S. Shetty, D. R. van der Westhuyzen, and N. R. Webb, "Quantitative analysis of SR-BI-dependent HDL retroendocytosis in hepatocytes and fibroblasts," Journal of Lipid Research, vol. 47, no. 8, pp. 1700-1713, 2006.

[44] E. Di Angelantonio, N. Sarwar, P. Perry et al., "Major lipids, apolipoproteins, and risk of vascular disease," Journal of the American Medical Association, vol. 302, no. 18, pp. 1993-2000, 2009.

[45] G. Assmann, H. Schulte, A. Von Eckardstein, and Y. Huang, "High-density lipoprotein cholesterol as a predictor of coronary heart disease risk. The PROCAM experience and pathophysiological implications for reverse cholesterol transport," Atherosclerosis, vol. 124, supplement, pp. S11-S20, 1996.

[46] G. Assmann, P. Cullen, and H. Schulte, “The Münster heart study (PROCAM). Results of follow-up at 8 years," European Heart Journal, vol. 19, supplement A, pp. A2-A11, 1998.

[47] P. S. Yusuf, S. Hawken, S. Ônpuu et al., "Effect of potentially modifiable risk factors associated with myocardial infarction in 52 countries (the INTERHEART study): case-control study," The Lancet, vol. 364, no. 9438, pp. 937-952, 2004.

[48] M. E. Brousseau, E. J. Schaefer, M. L. Wolfe et al., "Effects of an inhibitor of cholesteryl ester transfer protein on HDL cholesterol," The New England Journal of Medicine, vol. 350, no. 15, pp. 1505-1515, 2004.

[49] S. E. Nissen, J.-C. Tardif, S. J. Nicholls et al., "Effect of torcetrapib on the progression of coronary atherosclerosis," The New England Journal of Medicine, vol. 356, no. 13, pp. 1304-1316, 2007.

[50] J. J. P. Kastelein, S. I. Van Leuven, L. Burgess et al., "Effect of torcetrapib on carotid atherosclerosis in familial hypercholesterolemia," The New England Journal of Medicine, vol. 356, no. 16, pp. 1620-1630, 2007.

[51] M. Vergeer, M. L. Bots, S. I. Van Leuven et al., "Cholesteryl ester transfer protein inhibitor torcetrapib and off-target toxicity: a pooled analysis of the rating atherosclerotic disease change by imaging with a new CETP inhibitor (RADIANCE) trials," Circulation, vol. 118, no. 24, pp. 2515-2522, 2008.

[52] C. P. Cannon, H. M. Dansky, M. Davidson et al., "Design of the DEFINE trial: determining the efficacy and tolerability of CETP inhibition with anacetrapib," American Heart Journal, vol. 158, no. 4, pp. 513.e3-519.e3, 2009.

[53] J. M. Peacock, D. K. Arnett, L. D. Atwood et al., "Genome scan for quantitative trait loci linked to high-density lipoprotein cholesterol: the NHLBI Family Heart Study," Arteriosclerosis, Thrombosis, and Vascular Biology, vol. 21, no. 11, pp. 1823-1828, 2001.

[54] X. Wang and B. Paigen, "Genome-wide search for new genes controlling plasma lipid concentrations in mice and humans," Current Opinion in Lipidology, vol. 16, no. 2, pp. 127-137, 2005.

[55] C. F. Sing, J. H. Stengard, and S. L. R. Kardia, "Genes, environment and cardiovascular disease," Arteriosclerosis, Thrombosis, and Vascular Biology, vol. 23, pp. 1190-1196, 2003.

[56] A. von Eckardstein, "Differential diagnosis of familial high density lipoprotein deficiency syndromes," Atherosclerosis, vol. 186, no. 2, pp. 231-239, 2006.

[57] G. Franceschini, C. R. Sirtori, E. Bosisio et al., "Relationship of the phenotypic expression of the A-I Milano apoprotein with plasma lipid and lipoprotein patterns," Atherosclerosis, vol. 58, no. 1-3, pp. 159-174, 1985.

[58] G. Chiesa and C. R. Sirtori, "Apolipoprotein A-IMilano: current perspectives," Current Opinion in Lipidology, vol. 14, no. 2, pp. 159-163, 2003.

[59] J. F. Oram and J. W. Heinecke, "ATP-binding cassette transporter A1: a cell cholesterol exporter that protects against cardiovascular disease," Physiological Reviews, vol. 85, no. 4, pp. 1343-1372, 2005.

[60] J. L. Benton, J. Ding, M. Y. Tsai et al., "Associations between two common polymorphisms in the ABCAl gene and subclinical atherosclerosis. Multi-Ethnic Study of Atherosclerosis (MESA)," Atherosclerosis, vol. 193, no. 2, pp. 352-360, 2007.

[61] R. V. Andersen, H. H. Wittrup, A. Tybjærg-Hansen, R. Steffensen, P. Schnohr, and B. G. Nordestgaard, "Hepatic lipase mutations,elevated high-density lipoprotein cholesterol, and increased risk of ischemic heart disease: the Copenhagen City Heart Study," Journal of the American College of Cardiology, vol. 41, no. 11, pp. 1972-1982, 2003.

[62] B. F. Voight, G. M. Peloso, M. Orho-Melander et al., "Plasma HDL cholesterol and risk of myocardial infarction: a mendelian randomisation study," The Lancet, vol. 380, no. 9841, pp. 572580, 2012.

[63] C. L. Haase, R. Frikke-Schmidt, B. G. Nordestgaard et al., "Mutation in APOA1 predicts increased risk of ischaemic heart disease and total mortality without low HDL cholesterol levels," Journal of Internal Medicine, vol. 270, no. 2, pp. 136-146, 2011.

[64] V. I. Zannis, A. Chroni, and M. Krieger, "Role of apoA-I, ABCA1, LCAT, and SR-BI in the biogenesis of HDL," Journal of Molecular Medicine, vol. 84, no. 4, pp. 276-294, 2006.

[65] A. Rohatgi, A. Khera, J. D. Berry et al., "HDL cholesterol efflux capacity and incident cardiovascular events," The New England Journal of Medicine, vol. 371, no. 25, pp. 2383-2393, 2014.

[66] T. Vaisar, S. Pennathur, P. S. Green et al., "Shotgun proteomics implicates protease inhibition and complement activation in the antiinflammatory properties of HDL," The Journal of Clinical Investigation, vol. 117, no. 3, pp. 746-756, 2007.

[67] A. M. Shiflett, J. R. Bishop, A. Pahwa, and S. L. Hajduk, "Human high density lipoproteins are platforms for the assembly of multi-component innate immune complexes," Journal of Biological Chemistry, vol. 280, no. 38, pp. 32578-32585, 2005.

[68] E. J. Reschly, M. G. Sorci-Thomas, W. Sean Davidson, S. C. Meredith, C. A. Reardon, and G. S. Getz, "Apolipoprotein 
A-I alpha-helices 7 and 8 modulate high density lipoprotein subclass distribution," The Journal of Biological Chemistry, vol. 277, no. 12, pp. 9645-9654, 2002.

[69] M. Rizzo, J. Otvos, D. Nikolic, G. Montalto, P. P. Toth, and M. Banach, "Subfractions and subpopulations of HDL: an update," Current Medicinal Chemistry, vol. 21, no. 25, pp. 2881-2891, 2014.

[70] A. Kontush and M. J. Chapman, "Functionally defective highdensity lipoprotein: a new therapeutic target at the crossroads of dyslipidemia, inflammation, and atherosclerosis," Pharmacological Reviews, vol. 58, no. 3, pp. 342-374, 2006.

[71] C. Grunfeld, M. Pang, W. Doerrler, J. K. Shigenaga, P. Jensen, and K. R. Feingold, "Lipids, lipoproteins, triglyceride clearance, and cytokines in human immunodeficiency virus infection and the acquired immunodeficiency syndrome," Journal of Clinical Endocrinology and Metabolism, vol. 74, no. 5, pp. 1045-1052, 1992.

[72] C. Popa, M. G. Netea, P. L. C. M. van Riel, J. W. M. van der Meer, and A. F. H. Stalenhoef, "The role of TNF- $\alpha$ in chronic inflammatory conditions, intermediary metabolism, and cardiovascular risk," Journal of Lipid Research, vol. 48, no. 4, pp. 751-752, 2007.

[73] W. Khovidhunkit, R. A. Memon, K. R. Feingold, and C. Grunfeld, "Infection and inflammation-induced proatherogenic changes of lipoproteins," Journal of Infectious Diseases, vol. 181, supplement 3, pp. S462-S472, 2000.

[74] A. Chait, Y. H. Chang, J. F. Oram, and J. W. Heinecke, “Thematic review series: The immune system and atherogenesis. Lipoprotein-associated inflammatory proteins: markers or mediators of cardiovascular disease?" Journal of Lipid Research, vol. 46, no. 3, pp. 389-403, 2005.

[75] A. Hoang, A. J. Murphy, M. T. Coughlan et al., "Advanced glycation of apolipoprotein A-I impairs its anti-atherogenic properties," Diabetologia, vol. 50, no. 8, pp. 1770-1779, 2007.

[76] E. Nobecourt, M. J. Davies, B. E. Brown et al., "The impact of glycation on apolipoprotein A-I structure and its ability to activate lecithin:cholesterol acyltransferase," Diabetologia, vol. 50, no. 3, pp. 643-653, 2007.

[77] E. Nobécourt, F. Tabet, G. Lambert et al., "Nonenzymatic glycation impairs the antiinflammatory properties of apolipoprotein A-I," Arteriosclerosis, Thrombosis, and Vascular Biology, vol. 30, no. 4, pp. 766-772, 2010.

[78] A. C. Carr, M. R. McCall, and B. Frei, "Oxidation of LDL by myeloperoxidase and reactive nitrogen species: reaction pathways and antioxidant protection," Arteriosclerosis, Thrombosis, and Vascular Biology, vol. 20, no. 7, pp. 1716-1723, 2000.

[79] E. A. Podrez, D. Schmitt, H. F. Hoff, and S. L. Hazen, "Myeloperoxidase-generated reactive nitrogen species convert LDL into an atherogenic form in vitro," The Journal of Clinical Investigation, vol. 103, no. 11, pp. 1547-1560, 1999.

[80] A. Daugherty, J. L. Dunn, D. L. Rateri, and J. W. Heinecke, "Myeloperoxidase, a catalyst for lipoprotein oxidation, is expressed in human atherosclerotic lesions," The Journal of Clinical Investigation, vol. 94, no. 1, pp. 437-444, 1994.

[81] L. Zheng, M. Settle, G. Brubaker et al., "Localization of nitration and chlorination sites on apolipoprotein A-I catalyzed by myeloperoxidase in human atheroma and associated oxidative impairment in ABCA1-dependent cholesterol efflux from macrophages," The Journal of Biological Chemistry, vol. 280, no. 1 , pp. 38-47, 2005.

[82] B. Shao, G. Cavigiolio, N. Brot, M. N. Oda, and J. W. Heinecke, "Methionine oxidation impairs reverse cholesterol transport by apolipoprotein A-I," Proceedings of the National Academy of Sciences of the United States of America, vol. 105, no. 34, pp. 12224-12229, 2008.

[83] K.-H. Cho, D. M. Durbin, and A. Jonas, "Role of individual amino acids of apolipoprotein A-I in the activation of lecithin: cholesterol acyltransferase and in HDL rearrangements," Journal of Lipid Research, vol. 42, no. 3, pp. 379-389, 2001.

[84] B. Garner, A. R. Waldeck, P. K. Witting, K.-A. Rye, and R. Stocker, "Oxidation of high density lipoproteins. II. Evidence for direct reduction of lipid hydroperoxides by methionine residues of apolipoproteins AI and AII," Journal of Biological Chemistry, vol. 273, no. 11, pp. 6088-6095, 1998.

[85] B. Shao, M. N. Oda, C. Bergt et al., "Myeloperoxidase impairs ABCA1-dependent cholesterol efflux through methionine oxidation and site-specific tyrosine chlorination of apolipoprotein A-I," The Journal of Biological Chemistry, vol. 281, no. 14, pp. 9001-9004, 2006.

[86] G. Daniil, A. A. P. Phedonos, A. G. Holleboom et al., "Characterization of antioxidant/anti-inflammatory properties and apoAI-containing subpopulations of HDL from family subjects with monogenic low HDL disorders," Clinica Chimica Acta, vol. 412, no. 13-14, pp. 1213-1220, 2011.

[87] C. Cavelier, I. Lorenzi, L. Rohrer, and A. von Eckardstein, "Lipid efflux by the ATP-binding cassette transporters ABCA1 and ABCG1," Biochimica et Biophysica Acta, vol. 1761, no. 7, pp. 655666, 2006.

[88] C. Bergt, S. Pennathur, X. Fu et al., "The myeloperoxidase product hypochlorous acid oxidizes HDL in the human artery wall and impairs ABCA1-dependent cholesterol transport," Proceedings of the National Academy of Sciences of the United States of America, vol. 101, no. 35, pp. 13032-13037, 2004.

[89] B. Shao, S. Pennathur, and J. W. Heinecke, "Myeloperoxidase targets apolipoprotein A-I, the major high density lipoprotein protein, for site-specific oxidation in human atherosclerotic lesions," Journal of Biological Chemistry, vol. 287, no. 9, pp. 63756386, 2012.

[90] B. Shao, C. Tang, J. W. Heinecke, and J. F. Oram, "Oxidation of apolipoprotein A-I by myeloperoxidase impairs the initial interactions with ABCA1 required for signaling and cholesterol export," Journal of Lipid Research, vol. 51, no. 7, pp. 1849-1858, 2010.

[91] M. M. Hussain, "Intestinal lipid absorption and lipoprotein formation," Current Opinion in Lipidology, vol. 25, no. 3, pp. 200-206, 2014.

[92] E. J. Niesor, E. Chaput, J.-L. Mary et al., "Effect of compounds affecting ABCAl expression and CETP activity on the HDL pathway involved in intestinal absorption of lutein and zeaxanthin," Lipids, vol. 49, no. 12, pp. 1233-1243, 2014.

[93] N. Nicod and R. S. Parker, "Vitamin E secretion by Caco-2 monolayers to APOA1, but not to HDL, is vitamer selective," Journal of Nutrition, vol. 143, no. 10, pp. 1565-1572, 2013.

[94] M. de la Llera-Moya, D. Drazul-Schrader, B. F. Asztalos, M. Cuchel, D. J. Rader, and G. H. Rothblat, "The ability to promote efflux via ABCA1 determines the capacity of serum specimens with similar high-density lipoprotein cholesterol to remove cholesterol from macrophages," Arteriosclerosis, Thrombosis, and Vascular Biology, vol. 30, no. 4, pp. 796-801, 2010.

[95] A. Mulya, J.-Y. Lee, A. K. Gebre et al., "Initial interaction of apoA-I with ABCAl impacts in vivo metabolic fate of nascent HDL," Journal of Lipid Research, vol. 49, no. 11, pp. 2390-2401, 2008. 
[96] K.-A. Rye and P. J. Barter, "Formation and metabolism of prebeta-migrating, lipid-poor apolipoprotein A-I," Arteriosclerosis, Thrombosis, and Vascular Biology, vol. 24, no. 3, pp. 421-428, 2004.

[97] L. Zheng, B. Nukuna, M.-L. Brennan et al., "Apolipoprotein AI is a selective target for myeloperoxidase-catalyzed oxidation and function impairment in subjects with cardiovascular disease," Journal of Clinical Investigation, vol. 114, no. 4, pp. 529541, 2004.

[98] B. Pan, B. Yu, H. Ren et al., "High-density lipoprotein nitration and chlorination catalyzed by myeloperoxidase impair its effect of promoting endothelial repair," Free Radical Biology and Medicine, vol. 60, pp. 272-281, 2013.

[99] A. Urundhati, Y. Huang, J. A. Lupica, J. D. Smith, J. A. DiDonato, and S. L. Hazen, "Modification of high density lipoprotein by myeloperoxidase generates a pro-inflammatory particle," The Journal of Biological Chemistry, vol. 284, no. 45, pp. 3082530835, 2009.

[100] L. Perségol, M.-C. Brindisi, D. Rageot et al., "Oxidation-induced loss of the ability of HDL to counteract the inhibitory effect of oxidized LDL on vasorelaxation," Heart and Vessels, pp. 1-5, 2014.

[101] K. Wang and P. V. Subbaiah, "Importance of the free sulfhydryl groups of lecithin-cholesterol acyltransferase for its sensitivity to oxidative inactivation," Biochimica et Biophysica Acta: Molecular and Cell Biology of Lipids, vol. 1488, no. 3, pp. 268-277, 2000.

[102] G. K. Hovingh, B. A. Hutten, A. G. Holleboom et al., "Compromised LCAT function is associated with increased atherosclerosis," Circulation, vol. 112, no. 6, pp. 879-884, 2005.

[103] E. Gjone and B. Bergaust, "Corneal opacity in familial plasma cholesterol ester deficiency," Acta Ophthalmologica, vol. 47, no. 1, pp. 222-227, 1969.

[104] R. Scarpioni, C. Paties, and G. Bergonzi, "Dramatic atherosclerotic vascular burden in a patient with familial lecithin-cholesterol acyltransferase (LCAT) deficiency," Nephrology Dialysis Transplantation, vol. 23, no. 3, pp. 1074-1075, 2008.

[105] A. R. Tall, P. Costet, and N. Wang, "Regulation and mechanisms of macrophage cholesterol efflux," Journal of Clinical Investigation, vol. 110, no. 7, pp. 899-904, 2002.

[106] J. F. Oram, “Tangier disease and ABCA1," Biochimica et Biophysica Acta: Molecular and Cell Biology of Lipids, vol. 1529, no. 1-3, pp. 321-330, 2000.

[107] M. E. Brousseau, G. P. Eberhart, J. Dupuis et al., "Cellular cholesterol efflux in heterozygotes for Tangier disease is markedly reduced and correlates with high density lipoprotein cholesterol concentration and particle size," Journal of Lipid Research, vol. 41, no. 7, pp. 1125-1135, 2000.

[108] A. E. van der Velde and A. K. Groen, "Shifting gears: liver SRBI drives reverse cholesterol transport in macrophages," The Journal of Clinical Investigation, vol. 115, no. 10, pp. 2699-2701, 2005.

[109] A. Leiva, H. Verdejo, M. L. Benítez, A. Martínez, D. Busso, and A. Rigotti, "Mechanisms regulating hepatic SR-BI expression and their impact on HDL metabolism," Atherosclerosis, vol. 217, no. 2, pp. 299-307, 2011.

[110] M. L. Varban, F. Rinninger, N. Wang et al., “Targeted mutation reveals a central role for SR-BI in hepatic selective uptake of high density lipoprotein cholesterol," Proceedings of the National Academy of Sciences of the United States of America, vol. 95, no. 8, pp. 4619-4624, 1998.

[111] W. Zhu, S. Saddar, D. Seetharam et al., "The scavenger receptor class B type I adaptor protein PDZK1 maintains endothelial monolayer integrity," Circulation Research, vol. 102, no. 4, pp. 480-487, 2008.

[112] B. Pan, Y. Ma, H. Ren et al., "Diabetic HDL is dysfunctional in stimulating endothelial cell migration and proliferation due to down regulation of SR-BI expression," PLoS ONE, vol. 7, no. 11, Article ID e48530, 2012.

[113] S. A. Sorrentino, C. Besler, L. Rohrer et al., "Endothelial-vasoprotective effects of high-density lipoprotein are impaired in patients with type 2 diabetes mellitus but are improved after extended-release niacin therapy," Circulation, vol. 121, no. 1, pp. $110-122,2010$.

[114] M. C. de Beer, A. Ji, A. Jahangiri et al., "ATP binding cassette G1-dependent cholesterol efflux during inflammation," Journal of Lipid Research, vol. 52, no. 2, pp. 345-353, 2011.

[115] I. Kudo and M. Murakami, "Phospholipase $\mathrm{A}_{2}$ enzymes," Prostaglandins \& Other Lipid Mediators, vol. 68-69, pp. 3-58, 2002.

[116] R. H. Schaloske and E. A. Dennis, "The phospholipase A2 superfamily and its group numbering system," Biochimica et Biophysica Acta: Molecular and Cell Biology of Lipids, vol. 1761, no. 11, pp. 1246-1259, 2006.

[117] Z. Mallat, G. Lambeau, and A. Tedgui, "Lipoprotein-associated and secreted phospholipases $\mathrm{A}_{2}$ in cardiovascular disease: roles as biological effectors and biomarkers," Circulation, vol. 122, no. 21, pp. 2183-2200, 2010.

[118] F. C. de Beer, M. C. de Beer, D. R. van der Westhuyzen et al., "Secretory non-pancreatic phospholipase A2: influence on lipoprotein metabolism," Journal of Lipid Research, vol. 38, no. 11, pp. 2232-2239, 1997.

[119] P. Shridas, W. M. Bailey, F. Gizard et al., "Group X secretory phospholipase A2 negatively regulates ABCA1 and ABCG1 expression and cholesterol efflux in macrophages," Arteriosclerosis, Thrombosis, and Vascular Biology, vol. 30, no. 10, pp. 20142021, 2010.

[120] P. Jousilahti, V. Salomaa, V. Rasi, E. Vahtera, and T. Palosuo, "The association of c-reactive protein, serum amyloid a and fibrinogen with prevalent coronary heart disease-baseline findings of the PAIS project," Atherosclerosis, vol. 156, no. 2, pp. 451-456, 2001.

[121] A. S. Whitehead, M. C. de Beer, D. M. Steel et al., "Identification of novel members of the serum amyloid A protein superfamily as constitutive apolipoproteins of high density lipoprotein," The Journal of Biological Chemistry, vol. 267, no. 6, pp. 3862-3867, 1992.

[122] J. M. Wroblewski, A. Jahangiri, A. Ji, F. C. de Beer, D. R. van der Westhuyzen, and N. R. Webb, "Nascent HDL formation by hepatocytes is reduced by the concerted action of serum amyloid A and endothelial lipase," Journal of Lipid Research, vol. 52, no. 12, pp. 2255-2261, 2011.

[123] K. Kotani, T. Yamada, and A. Gugliucci, "Paired measurements of paraoxonase 1 and serum amyloid A as useful disease markers," BioMed Research International, vol. 2013, Article ID 481437, 4 pages, 2013.

[124] T. Vaisar, C. Tang, I. Babenko et al., "Inflammatory remodeling of the HDL proteome impairs cholesterol efflux capacity," Journal of Lipid Research, vol. 56, no. 8, pp. 1519-1530, 2015.

[125] M. Aviram, M. Rosenblat, C. L. Bisgaier, R. S. Newton, S. L. Primo-Parmo, and B. N. La Du, "Paraoxonase inhibits highdensity lipoprotein oxidation and preserves its functions: a possible peroxidative role for paraoxonase," Journal of Clinical Investigation, vol. 101, no. 8, pp. 1581-1590, 1998. 
[126] C. Mineo and P. W. Shaul, "PON-dering differences in HDL function in coronary artery disease," The Journal of Clinical Investigation, vol. 121, no. 7, pp. 2545-2548, 2011.

[127] L. Jaouad, C. Milochevitch, and A. Khalil, "PON1 paraoxonase activity is reduced during HDL oxidation and is an indicator of HDL antioxidant capacity," Free Radical Research, vol. 37, no. 1, pp. 77-83, 2003.

[128] T. Bacchetti, S. Masciangelo, T. Armeni, V. Bicchiega, and G. Ferretti, "Glycation of human high density lipoprotein by methylglyoxal: effect on HDL-paraoxonase activity," Metabolism, vol. 63, no. 3, pp. 307-311, 2014.

[129] B. Mackness, P. N. Durrington, B. Abuashia, A. J. M. Boulton, and M. I. Mackness, "Low paraoxonase activity in type II diabetes mellitus complicated by retinopathy," Clinical Science, vol. 98, no. 3, pp. 355-363, 2000.

[130] S. K. Kota, L. K. Meher, S. K. Kota, S. Jammula, S. V. Krishna, and K. D. Modi, "Implications of serum paraoxonase activity in obesity, diabetes mellitus, and dyslipidemia," Indian Journal of Endocrinology and Metabolism, vol. 17, no. 3, pp. 402-412, 2013.

[131] Y. Huang, Z. Wu, M. Riwanto et al., "Myeloperoxidase, paraoxonase-1, and HDL form a functional ternary complex," Journal of Clinical Investigation, vol. 123, no. 9, pp. 3815-3828, 2013.

[132] P. S. MacLean, C. J. Tanner, J. A. Houmard, and H. A. Barakat, "Plasma cholesteryl ester transfer protein activity is not linked to insulin sensitivity," Metabolism, vol. 50, no. 7, pp. 783-788, 2001.

[133] S. M. Boekholdt, F. M. Sacks, J. W. Jukema et al., "Cholesteryl ester transfer protein TaqIB variant, high-density lipoprotein cholesterol levels, cardiovascular risk, and efficacy of pravastatin treatment: individual patient meta-analysis of 13677 subjects," Circulation, vol. 111, no. 3, pp. 278-287, 2005.

[134] A. Inazu, X.-C. Jiang, T. Haraki et al., "Genetic cholesteryl ester transfer protein deficiency caused by two prevalent mutations as a major determinant of increased levels of high density lipoprotein cholesterol," Journal of Clinical Investigation, vol. 94, no. 5, pp. 1872-1882, 1994.

[135] K.-I. Hirano, S. Yamashita, N. Nakajima et al., "Genetic cholesteryl ester transfer protein deficiency is extremely frequent in the Omagari area of Japan. Marked hyperalphalipoproteinemia caused by CETP gene mutation is not associated with longevity," Arteriosclerosis, Thrombosis, and Vascular Biology, vol. 17, no. 6, pp. 1053-1059, 1997.

[136] S. Yamashita, T. Maruyama, K.-I. Hirano, N. Sakai, N. Nakajima, and Y. Matsuzawa, "Molecular mechanisms, lipoprotein abnormalities and atherogenicity of hyperalphalipoproteinemia," Atherosclerosis, vol. 152, no. 2, pp. 271-285, 2000.

[137] P. Wiesner, K. Leidl, A. Boettcher, G. Schmitz, and G. Liebisch, "Lipid profiling of FPLC-separated lipoprotein fractions by electrospray ionization tandem mass spectrometry," Journal of Lipid Research, vol. 50, no. 3, pp. 574-585, 2009.

[138] A. Kontush, M. Lhomme, and M. J. Chapman, "Unraveling the complexities of the HDL lipidome," Journal of Lipid Research, vol. 54, no. 11, pp. 2950-2963, 2013.

[139] K. Sattler and B. Levkau, "Sphingosine-1-phosphate as a mediator of high-density lipoprotein effects in cardiovascular protection," Cardiovascular Research, vol. 82, no. 2, pp. 201-211, 2009.

[140] V. H. Sunesen, C. Weber, and G. Hølmer, "Lipophilic antioxidants and polyunsaturated fatty acids in lipoprotein classes: distribution and interaction," European Journal of Clinical Nutrition, vol. 55, no. 2, pp. 115-123, 2001.
[141] W. Pruzanski, E. Stefanski, F. C. de Beer, M. C. de Beer, A. Ravandi, and A. Kuksis, "Comparative analysis of lipid composition of normal and acute-phase high density lipoproteins," Journal of Lipid Research, vol. 41, no. 7, pp. 1035-1047, 2000.

[142] A. Kontush, E. C. de Faria, S. Chantepie, and M. J. Chapman, "A normotriglyceridemic, low HDL-cholesterol phenotype is characterised by elevated oxidative stress and HDL particles with attenuated antioxidative activity," Atherosclerosis, vol. 182, no. 2, pp. 277-285, 2005.

[143] D. J. Greene, J. W. Skeggs, and R. E. Morton, "Elevated triglyceride content diminishes the capacity of high density lipoprotein to deliver cholesteryl esters via the scavenger receptor class B type I (SR-BI)," The Journal of Biological Chemistry, vol. 276, no. 7, pp. 4804-4811, 2001.

[144] W. Pruzanski, E. Stefanski, F. C. de Beer et al., "Lipoproteins are substrates for human secretory group IIA phospholipase $\mathrm{A}_{2}$ : preferential hydrolysis of acute phase HDL," Journal of Lipid Research, vol. 39, no. 11, pp. 2150-2160, 1998.

[145] S. Kar, M. A. Patel, R. K. Tripathy, P. Bajaj, U. V. Suvarnakar, and A. H. Pande, "Oxidized phospholipid content destabilizes the structure of reconstituted high density lipoprotein particles and changes their function," Biochimica et Biophysica ActaMolecular and Cell Biology of Lipids, vol. 1821, no. 9, pp. 12001210, 2012.

[146] A. Papathanasiou, C. Kostara, M.-T. Cung et al., "Analysis of the composition of plasma lipoproteins in patients with extensive coronary heart disease using $1 \mathrm{H}$ NMR spectroscopy," Hellenic Journal of Cardiology, vol. 49, no. 2, pp. 72-78, 2008.

[147] U. J. F. Tietge, C. Maugeais, S. Lund-Katz, D. Grass, F. C. DeBeer, and D. J. Rader, "Human secretory phospholipase $\mathrm{A}_{2}$ mediates decreased plasma levels of HDL cholesterol and ApoA-I in response to inflammation in human ApoA-I transgenic mice," Arteriosclerosis, Thrombosis, and Vascular Biology, vol. 22, no. 7, pp. 1213-1218, 2002.

[148] P. G. Yancey, M. de la Llera-Moya, S. Swarnakar et al., "High density lipoprotein phospholipid composition is a major determinant of the bi-directional flux and net movement of cellular free cholesterol mediated by scavenger receptor BI," Journal of Biological Chemistry, vol. 275, no. 47, pp. 36596-36604, 2000.

[149] M. Bamberger, S. Lund-Katz, M. C. Phillips, and G. H. Rothblat, "Mechanism of the hepatic lipase induced accumulation of high-density lipoprotein cholesterol by cells in culture," Biochemistry, vol. 24, no. 14, pp. 3693-3701, 1985.

[150] A. Zerrad-Saadi, P. Therond, S. Chantepie et al., "HDL3-mediated inactivation of LDL-associated phospholipid hydroperoxides is determined by the redox status of apolipoprotein A-I and HDL particle surface lipid rigidity: relevance to inflammation and atherogenesis," Arteriosclerosis, Thrombosis, and Vascular Biology, vol. 29, no. 12, pp. 2169-2175, 2009.

[151] M. I. Mackness, P. N. Durrington, and B. Mackness, "How high-density lipoprotein protects against the effects of lipid peroxidation," Current Opinion in Lipidology, vol. 11, no. 4, pp. 383-388, 2000.

[152] S. Mitra, T. Goyal, and J. L. Mehta, "Oxidized LDL, LOX-1 and atherosclerosis," Cardiovascular Drugs and Therapy, vol. 25, no. 5, pp. 419-429, 2011.

[153] A. D. Watson, N. Leitinger, M. Navab et al., "Structural identification by mass spectrometry of oxidized phospholipids in minimally oxidized low density lipoprotein that induce monocyte/endothelial interactions and evidence for their presence in vivo," The Journal of Biological Chemistry, vol. 272, no. 21, pp. 13597-13607, 1997. 
[154] S. D. Cushing, J. A. Berliner, A. J. Valente et al., "Minimally modified low density lipoprotein induces monocyte chemotactic protein 1 in human endothelial cells and smooth muscle cells," Proceedings of the National Academy of Sciences of the United States of America, vol. 87, no. 13, pp. 5134-5138, 1990.

[155] W. Jaross, R. Eckey, and M. Menschikowski, "Biological effects of secretory phospholipase $\mathrm{A}_{2}$ group IIA on lipoproteins and in atherogenesis," European Journal of Clinical Investigation, vol. 32, no. 6, pp. 383-393, 2002.

[156] Y. Ishimoto, K. Yamada, S. Yamamoto, T. Ono, M. Notoya, and K. Hanasaki, "Group V and X secretory phospholipase $\mathrm{A}_{2} \mathrm{~s}$-induced modification of high-density lipoprotein linked to the reduction of its antiatherogenic functions," Biochimica et Biophysica Acta: Molecular Cell Research, vol. 1642, no. 3, pp. 129-138, 2003.

[157] D. Mannheim, J. Herrmann, D. Versari et al., "Enhanced expression of Lp-PLA2 and lysophosphatidylcholine in symptomatic carotid atherosclerotic plaques," Stroke, vol. 39, no. 5, pp. 14481455, 2008.

[158] T. Kita, N. Kume, M. Minami et al., "Role of oxidized LDL in atherosclerosis," Annals of the New York Academy of Sciences, vol. 947, pp. 199-205, 2001.

[159] F. Rached, M. Lhomme, L. Camont et al., "Defective functionality of small, dense HDL3 subpopulations in ST segment elevation myocardial infarction: relevance of enrichment in lysophosphatidylcholine, phosphatidic acid and serum amyloid A," Biochimica et Biophysica Acta-Molecular and Cell Biology of Lipids, vol. 1851, no. 9, pp. 1254-1261, 2015.

[160] N. Leitinger, A. D. Watson, S. Y. Hama et al., "Role of group II secretory phospholipase $\mathrm{A}_{2}$ in atherosclerosis: 2 potential involvement of biologically active oxidized phospholipids," Arteriosclerosis, Thrombosis, and Vascular Biology, vol. 19, no. 5, pp. 1291-1298, 1999.

[161] C. Morgantini, A. Natali, B. Boldrini et al., "Anti-inflammatory and antioxidant properties of HDLs are impaired in type 2 diabetes," Diabetes, vol. 60, no. 10, pp. 2617-2623, 2011.

[162] Y. Wang and J. F. Oram, "Unsaturated fatty acids inhibit cholesterol efflux from macrophages by increasing degradation of ATP-binding cassette transporter A1," The Journal of Biological Chemistry, vol. 277, no. 7, pp. 5692-5697, 2002.

[163] Y. Uehara, S.-I. Miura, A. von Eckardstein et al., "Unsaturated fatty acids suppress the expression of the ATP-binding cassette transporter G1 (ABCG1) and ABCA1 genes via an LXR/RXR responsive element," Atherosclerosis, vol. 191, no. 1, pp. 11-21, 2007.

[164] Y. Wang and J. F. Oram, "Unsaturated fatty acids phosphorylate and destabilize ABCA1 through a protein kinase C $\delta$ pathway," Journal of Lipid Research, vol. 48, no. 5, pp. 1062-1068, 2007.

[165] A. Carro, M. Martín, I. Lozano, and S. Hevia, "Low HDL-C: more than atherosclerosis," Cardiocore, vol. 46, no. 3, pp. e39e41, 2011.

[166] M. McMahon, J. Grossman, J. FitzGerald et al., "Proinflammatory high-density lipoprotein as a biomarker for atherosclerosis in patients with systemic lupus erythematosus and rheumatoid arthritis," Arthritis and Rheumatism, vol. 54, no. 8, pp. 25412549, 2006.

[167] M. McMahon, J. Grossman, B. Skaggs et al., "Dysfunctional proinflammatory high-density lipoproteins confer increased risk of atherosclerosis in women with systemic lupus erythematosus," Arthritis and Rheumatism, vol. 60, no. 8, pp. 24282437, 2009.
[168] D. Farbstein and A. P. Levy, "HDL dysfunction in diabetes: causes and possible treatments," Expert Review of Cardiovascular Therapy, vol. 10, no. 3, pp. 353-361, 2012.

[169] L. R. Brunham, J. K. Kruit, J. Iqbal et al., "Intestinal ABCA1 directly contributes to HDL biogenesis in vivo," Journal of Clinical Investigation, vol. 116, no. 4, pp. 1052-1062, 2006.

[170] Y. Zhang, F. C. McGillicuddy, C. C. Hinkle et al., "Adipocyte modulation of high-density lipoprotein cholesterol," Circulation, vol. 121, no. 11, pp. 1347-1355, 2010.

[171] S. Le Lay, C. Robichon, X. Le Liepvre, G. Dagher, P. Ferre, and I. Dugail, "Regulation of ABCA1 expression and cholesterol efflux during adipose differentiation of 3T3-L1 cells," Journal of Lipid Research, vol. 44, no. 8, pp. 1499-1507, 2003.

[172] C. N. Lumeng, S. M. DeYoung, J. L. Bodzin, and A. R. Saltiel, "Increased inflammatory properties of adipose tissue macrophages recruited during diet-induced obesity," Diabetes, vol. 56, no. 1, pp. 16-23, 2007.

[173] S. J. Nicholls, P. Lundman, J. A. Harmer et al., "Consumption of saturated fat impairs the anti-inflammatory properties of highdensity lipoproteins and endothelial function," Journal of the American College of Cardiology, vol. 48, no. 4, pp. 715-720, 2006.

[174] C. K. Roberts, M. Katiraie, D. M. Croymans, O. O. Yang, and T. Kelesidis, "Untrained young men have dysfunctional HDL compared with strength-trained men irrespective of body weight status," Journal of Applied Physiology, vol. 115, no. 7, pp. 1043-1049, 2013.

[175] B.-M. He, S.-P. Zhao, and Z.-Y. Peng, "Effects of cigarette smoking on HDL quantity and function: implications for atherosclerosis," Journal of Cellular Biochemistry, vol. 114, no. 11, pp. 2431-2436, 2013.

[176] R. Aebersold and B. F. Cravatt, "Proteomics-advances, applications and the challenges that remain," Trends in Biotechnology, vol. 20, no. 12, supplement, pp. 1-2, 2002.

[177] B. Brügger, "Lipidomics: analysis of the lipid composition of cells and Subcellular organelles by electrospray ionization mass spectrometry," Annual Review of Biochemistry, vol. 83, pp. 7998, 2014.

[178] P. J. Barter, S. Nicholls, K.-A. Rye, G. M. Anantharamaiah, M. Navab, and A. M. Fogelman, "Antiinflammatory properties of HDL," Circulation Research, vol. 95, no. 8, pp. 764-772, 2004.

[179] C. Wadham, N. Albanese, J. Roberts et al., "High-density lipoproteins neutralize C-reactive protein proinflammatory activity," Circulation, vol. 109, no. 17, pp. 2116-2122, 2004.

[180] M. G. Sorci-Thomas and M. J. Thomas, "Why targeting HDL should work as a therapeutic tool, but has not," Journal of Cardiovascular Pharmacology, vol. 62, no. 3, pp. 239-246, 2013.

[181] J.-Y. Hsieh, C.-T. Chang, M. T. Huang et al., "Biochemical and functional characterization of charge-defined subfractions of high-density lipoprotein from normal adults," Analytical Chemistry, vol. 85, no. 23, pp. 11440-11448, 2013.

[182] W. S. Davidson, R. A. G. D. Silva, S. Chantepie, W. R. Lagor, M. J. Chapman, and A. Kontush, "Proteomic analysis of defined hdl subpopulations reveals particle-specific protein clusters: relevance to antioxidative function," Arteriosclerosis, Thrombosis, and Vascular Biology, vol. 29, no. 6, pp. 870-876, 2009.

[183] J. W. Heinecke, "The HDL proteome: a marker-and perhaps mediator-of coronary artery disease," The Journal of Lipid Research, vol. 50, supplement, pp. S167-S171, 2009.

[184] D. Nedelkov, "Mass spectrometry-based immunoassays for the next phase of clinical applications," Expert Review of Proteomics, vol. 3, no. 6, pp. 631-640, 2006. 
[185] O. Trenchevska and D. Nedelkov, "Targeted quantitative mass spectrometric immunoassay for human protein variants," Proteome Science, vol. 9, no. 1, article 19, 2011.

[186] H. Yassine, C. R. Borges, M. R. Schaab et al., "Mass spectrometric immunoassay and MRM as targeted MS-based quantitative approaches in biomarker development: potential applications to cardiovascular disease and diabetes," Proteomics: Clinical Applications, vol. 7, no. 7-8, pp. 528-540, 2013.

[187] A. N. Hoofnagle and M. H. Wener, "The fundamental flaws of immunoassays and potential solutions using tandem mass spectrometry," Journal of Immunological Methods, vol. 347, no. 1-2, pp. 3-11, 2009.

[188] T. Shi, D. Su, T. Liu et al., "Advancing the sensitivity of selected reaction monitoring-based targeted quantitative proteomics," Proteomics, vol. 12, no. 8, pp. 1074-1092, 2012.

[189] G. E. Ronsein, N. Pamir, P. D. von Haller et al., "Parallel reaction monitoring (PRM) and selected reaction monitoring (SRM) exhibit comparable linearity, dynamic range and precision for targeted quantitative HDL proteomics," Journal of Proteomics, vol. 113, pp. 388-399, 2015.

[190] T. A. Addona, S. E. Abbatiello, B. Schilling et al., "Multi-site assessment of the precision and reproducibility of multiple reaction monitoring-based measurements of proteins in plasma," Nature Biotechnology, vol. 27, no. 7, pp. 633-641, 2009.

[191] H. N. Yassine, A. M. Jackson, C. R. Borges et al., "The application of multiple reaction monitoring and multi-analyte profiling to HDL proteins," Lipids in Health and Disease, vol. 13, article 8, 2014.

[192] H. Karlsson, P. Leanderson, C. Tagesson, and M. Lindahl, "Lipoproteomics II: mapping of proteins in high-density lipoprotein using two-dimensional gel electrophoresis and mass spectrometry," Proteomics, vol. 5, no. 5, pp. 1431-1445, 2005.

[193] F. Rezaee, B. Casetta, J. H. M. Levels, D. Speijer, and J. C. M. Meijers, "Proteomic analysis of high-density lipoprotein," Proteomics, vol. 6, no. 2, pp. 721-730, 2006.

[194] J. Patzelt, A. Verschoor, and H. F. Langer, "Platelets and the complement cascade in atherosclerosis," Frontiers in Physiology, vol. 6, article 49, 2015.

[195] A. K. Chauhan and T. L. Moore, "Presence of plasma complement regulatory proteins clusterin (Apo $\mathrm{J}$ ) and vitronectin (S40) on circulating immune complexes (CIC)," Clinical and Experimental Immunology, vol. 145, no. 3, pp. 398-406, 2006.

[196] S. I. Rosenfeld, C. H. Packman, and J. P. Leddy, "Inhibition of the lytic action of cell-bound terminal complement components by human high density lipoproteins and apoproteins," The Journal of Clinical Investigation, vol. 71, no. 4, pp. 795-808, 1983.

[197] K. K. Hamilton, J. Zhao, and P. J. Sims, "Interaction between apolipoproteins A-I and A-II and the membrane attack complex of complement. Affinity of the apoproteins for polymeric C9," Journal of Biological Chemistry, vol. 268, no. 5, pp. 3632-3638, 1993.

[198] A. L. Pasqui, L. Puccetti, G. Bova et al., "Relationship between serum complement and different lipid disorders," Clinical \& Experimental Medicine, vol. 2, no. 1, pp. 33-38, 2002.

[199] J. Wagner, M. Riwanto, C. Besler et al., "Characterization of levels and cellular transfer of circulating lipoprotein-bound microRNAs," Arteriosclerosis, Thrombosis, and Vascular Biology, vol. 33, no. 6, pp. 1392-1400, 2013.

[200] F. Momen-Heravi, L. Balaj, S. Alian et al., "Current methods for the isolation of extracellular vesicles," Biological Chemistry, vol. 394, no. 10, pp. 1253-1262, 2013.
[201] É. Biró, J. M. van den Goor, B. A. de Mol et al., “Complement activation on the surface of cell-derived microparticles during cardiac surgery with cardiopulmonary bypass-is retransfusion of pericardial blood harmful?" Perfusion, vol. 26, no. 1, pp. 2129, 2011.

[202] A. M. Shiflett, J. R. Bishop, A. Pahwa, and S. L. Hajduk, "Human high density lipoproteins are platforms for the assembly of multi-component innate immune complexes," The Journal of Biological Chemistry, vol. 280, no. 38, pp. 32578-32585, 2005.

[203] J. M. Harrington, T. Nishanova, S. R. Pena et al., "A retained secretory signal peptide mediates high density lipoprotein (HDL) assembly and function of haptoglobin-related protein," Journal of Biological Chemistry, vol. 289, no. 36, pp. 24811-24820, 2014.

[204] J. Widener, M. J. Nielsen, A. Shiflett, S. K. Moestrup, and S. Hajduk, "Hemoglobin is a co-factor of human trypanosome lytic factor," PLoS Pathog, vol. 3, no. 9, article e129, 2008.

[205] M. Sanson, E. Distel, and E. A. Fisher, "HDL induces the expression of the M2 macrophage markers arginase 1 and Fizz-1 in a STAT6-dependent process," PLoS ONE, vol. 8, no. 8, Article ID e74676, 2013.

[206] J. Marsillach, J. O. Becker, T. Vaisar et al., "Paraoxonase-3 is depleted from the high-density lipoproteins of autoimmune disease patients with subclinical atherosclerosis," Journal of Proteome Research, vol. 14, no. 5, pp. 2046-2054, 2015.

[207] P. Malmberg, K. Börner, Y. Chen et al., "Localization of lipids in the aortic wall with imaging TOF-SIMS," Biochimica et Biophysica Acta: Molecular and Cell Biology of Lipids, vol. 1771, no. 2, pp. 185-195, 2007.

[208] M. R. M. Domingues, A. Reis, and P. Domingues, "Mass spectrometry analysis of oxidized phospholipids," Chemistry and Physics of Lipids, vol. 156, no. 1-2, pp. 1-12, 2008.

[209] A. J. Lepedda, A. Cigliano, G. M. Cherchi et al., "A proteomic approach to differentiate histologically classified stable and unstable plaques from human carotid arteries," Atherosclerosis, vol. 203, no. 1, pp. 112-118, 2009.

[210] A. J. Lepedda, A. Zinellu, G. Nieddu et al., "Protein sulfhydryl group oxidation and mixed-disulfide modifications in stable and unstable human carotid plaques," Oxidative Medicine and Cellular Longevity, vol. 2013, Article ID 403973, 8 pages, 2013.

[211] F. M. Faraci and S. P. Didion, "Vascular protection: superoxide dismutase isoforms in the vessel wall," Arteriosclerosis, Thrombosis, and Vascular Biology, vol. 24, no. 8, pp. 1367-1373, 2004.

[212] S. L. Harley, J. Sturge, and J. T. Powell, "Regulation by fibrinogen and its products of intercellular adhesion molecule-1 expression in human saphenous vein endothelial cells," Arteriosclerosis, Thrombosis, and Vascular Biology, vol. 20, no. 3, pp. 652-658, 2000.

[213] N. G. He, S. Awasthi, S. S. Singhal, M. B. Trent, and P. J. Boor, "The role of glutathione S-transferases as a defense against reactive electrophiles in the blood vessel wall," Toxicology and Applied Pharmacology, vol. 152, no. 1, pp. 83-89, 1998.

[214] J. L. Martin-Ventura, V. Nicolas, X. Houard et al., "Biological significance of decreased HSP27 in human atherosclerosis," Arteriosclerosis, Thrombosis, and Vascular Biology, vol. 26, no. 6, pp. 1337-1343, 2006.

[215] G. J. Won, S. K. Hye, K.-G. Park et al., "Analysis of proteome and transcriptome of tumor necrosis factor $\alpha$ stimulated vascular smooth muscle cells with or without alpha lipoic acid," Proteomics, vol. 4, no. 11, pp. 3383-3393, 2004.

[216] H. Kaji, "High-density lipoproteins and the immune system," Journal of Lipids, vol. 2013, Article ID 684903, 8 pages, 2013. 
[217] B. Arnesjö, B. Danielsson, R. Ekman, B. G. Johansson, and B. G. Petersson, "Characterization of high density lipoproteins in human cholestasis," Scandinavian Journal of Clinical and Laboratory Investigation, vol. 37, no. 7, pp. 587-597, 1977.

[218] P. H. Joshi, P. P. Toth, S. T. Lirette et al., "Association of highdensity lipoprotein subclasses and incident coronary heart disease: The Jackson Heart and Framingham Offspring Cohort Studies," European Journal of Preventive Cardiology, 2014.

[219] D. S. Kim, A. A. Burt, E. A. Rosenthal et al., "HDL-3 is a superior predictor of carotid artery disease in a case-control cohort of 1725 participants," Journal of the American Heart Association, vol. 3, no. 3, Article ID e000902, 2014.

[220] S. S. Martin, A. A. Khokhar, H. T. May et al., "HDL cholesterol subclasses, myocardial infarction, and mortality in secondary prevention: the Lipoprotein Investigators Collaborative," European Heart Journal, vol. 36, no. 1, pp. 22-30, 2015.

[221] A. V. G. Edwards, M. Y. White, and S. J. Cordwell, "The role of proteomics in clinical cardiovascular biomarker discovery," Molecular \& Cellular Proteomics, vol. 7, no. 10, pp. 1824-1837, 2008.

[222] Y. Tan, T. R. Liu, S. W. Hu et al., "Acute coronary syndrome remodels the protein cargo and functions of high-density lipoprotein subfractions," PLoS ONE, vol. 9, no. 4, Article ID e94264, 2014.

[223] L.-R. Yan, D.-X. Wang, H. Liu et al., "A pro-atherogenic HDL profile in coronary heart disease patients: an iTRAQ labellingbased proteomic approach," PLoS ONE, vol. 9, no. 5, Article ID e98368, 2014.

[224] A. J. Lepedda, G. Nieddu, E. Zinellu et al., "Proteomic analysis of plasma-purified VLDL, LDL, and HDL fractions from atherosclerotic patients undergoing carotid endarterectomy: Identification of serum amyloid a as a potential marker," Oxidative Medicine and Cellular Longevity, vol. 2013, Article ID 385214, 11 pages, 2013.

[225] M. Ståhlman, B. Fagerberg, M. Adiels et al., "Dyslipidemia, but not hyperglycemia and insulin resistance, is associated with marked alterations in the HDL lipidome in type 2 diabetic subjects in the DIWA cohort: impact on small HDL particles," Biochimica et Biophysica Acta-Molecular and Cell Biology of Lipids, vol. 1831, no. 11, pp. 1609-1617, 2013.

[226] M. Holzer, R. Birner-Gruenberger, T. Stojakovic et al., "Uremia alters HDL composition and function," Journal of the American Society of Nephrology, vol. 22, no. 9, pp. 1631-1641, 2011.

[227] A. Mangé, A. Goux, S. Badiou et al., "HDL proteome in hemodialysis patients: a quantitative nanoflow liquid chromatography-tandem mass spectrometry approach," PLOS ONE, vol. 7, no. 3, Article ID e34107, 2012.

[228] C. Kopecky, B. Genser, C. Drechsler et al., "Quantification of HDL proteins, cardiac events, and mortality in patients with type 2 diabetes on hemodialysis," Clinical Journal of the American Society of Nephrology, vol. 10, no. 2, pp. 224-231, 2015.

[229] J. Watanabe, C. Charles-Schoeman, Y. Miao et al., "Proteomic profiling following immunoaffinity capture of high-density lipoprotein: association of acute-phase proteins and complement factors with proinflammatory high-density lipoprotein in rheumatoid arthritis," Arthritis and Rheumatism, vol. 64, no. 6, pp. 1828-1837, 2012.

[230] T. Weichhart, C. Kopecky, M. Kubicek et al., "Serum amyloid A in uremic HDL promotes inflammation," Journal of the American Society of Nephrology, vol. 23, no. 5, pp. 934-947, 2012.

[231] H. N. Yassine, A. M. Jackson, P. D. Reaven et al., "The application of multiple reaction monitoring to assess ApoA-I methionine oxidations in diabetes and cardiovascular disease," Translational Proteomics, vol. 4-5, pp. 18-24, 2014.

[232] M. K. Jensen, E. B. Rimm, J. D. Furtado, and F. M. Sacks, "Apolipoprotein C-III as a potential modulator of the association between HDL-cholesterol and incident coronary heart disease," Journal of the American Heart Association, vol. 1, no. 2, Article ID e000232, 2012.

[233] M. Kosuge, T. Ebina, T. Ishikawa et al., "Serum amyloid A is a better predictor of clinical outcomes than C-reactive protein in non-ST-segment elevation acute coronary syndromes," Circulation Journal, vol. 71, no. 2, pp. 186-190, 2007.

[234] K. Alwaili, D. Bailey, Z. Awan et al., "The HDL proteome in acute coronary syndromes shifts to an inflammatory profile," Biochimica et Biophysica Acta-Molecular and Cell Biology of Lipids, vol. 1821, no. 3, pp. 405-415, 2012.

[235] D. P. Cormode, J. C. Frias, Y. Ma et al., "HDL as a contrast agent for medical imaging," Future Lipidology, vol. 4, no. 4, pp. 493500, 2009.

[236] P. S. Green, T. Vaisar, S. Pennathur et al., "Combined statin and niacin therapy remodels the high-density lipoprotein proteome," Circulation, vol. 118, no. 12, pp. 1259-1267, 2008.

[237] R. Laaksonen, M. T. Jänis, and M. Oresic, "Lipidomics-based safety biomarkers for lipid-lowering treatments," Angiology, vol. 59, no. 2, pp. 65S-68S, 2008.

[238] A. Keech, R. J. Simes, P. Barter et al., "Effects of long-term fenofibrate therapy on cardiovascular events in 9795 people with type 2 diabetes mellitus (the FIELD study): randomised controlled trial," The Lancet, vol. 366, no. 9500, pp. 1849-1861, 2005.

[239] P. V. Subbaiah and M. Liu, "Role of sphingomyelin in the regulation of cholesterol esterification in the plasma lipoproteins. Inhibition of lecithin-cholesterol acyltransferase reaction," The Journal of Biological Chemistry, vol. 268, no. 27, pp. 20156-20163, 1993.

[240] L. Yetukuri, I. Huopaniemi, A. Koivuniemi et al., "High density lipoprotein structural changes and drug response in lipidomic profiles following the long-term fenofibrate therapy in the FIELD substudy," PLoS ONE, vol. 6, no. 8, Article ID e23589, 2011.

[241] M. F. Lopez, B. Krastins, D. A. Sarracino et al., "Proteomic signatures of serum albumin-bound proteins from stroke patients with and without endovascular closure of PFO are significantly different and suggest a novel mechanism for cholesterol efflux," Clinical Proteomics, vol. 12, no. 1, article 2, 2015.

[242] M. C. Ochoa, J. Fioravanti, I. Rodriguez et al., "Antitumor immunotherapeutic and toxic properties of an HDL-conjugated chimeric IL-15 fusion protein," Cancer Research, vol. 73, no. 1, pp. 139-149, 2013.

[243] J. Fioravanti, I. González, J. Medina-Echeverz et al., "Anchoring interferon alpha to apolipoprotein A-I reduces hematological toxicity while enhancing immunostimulatory properties," Hepatology, vol. 53, no. 6, pp. 1864-1873, 2011.

[244] C. E. Kostara, A. Papathanasiou, N. Psychogios et al., "NMRbased lipidomic analysis of blood lipoproteins differentiates the progression of coronary heart disease," Journal of Proteome Research, vol. 13, no. 5, pp. 2585-2598, 2014.

[245] C. E. Kostara, A. Papathanasiou, M. T. Cung, M. S. Elisaf, J. Goudevenos, and E. T. Bairaktari, "Evaluation of established coronary heart disease on the basis of HDL and non-HDL NMR lipid profiling," Journal of Proteome Research, vol. 9, no. 2, pp. 897-911, 2010. 
[246] C. Morgantini, D. Meriwether, S. Baldi et al., "HDL lipid composition is profoundly altered in patients with type 2 diabetes and atherosclerotic vascular disease," Nutrition, Metabolism and Cardiovascular Diseases, vol. 24, no. 6, pp. 594-599, 2014.

[247] C. R. Sirtori, L. Calabresi, G. Franceschini et al., "Cardiovascular status of carriers of the apolipoprotein A-I Milano mutant: the limone sul garda study," Circulation, vol. 103, no. 15, pp. 19491954, 2001.

[248] G. G. Schwartz, A. G. Olsson, M. Abt et al., "Effects of dalcetrapib in patients with a recent acute coronary syndrome," The New England Journal of Medicine, vol. 367, no. 22, pp. 20892099, 2012. 


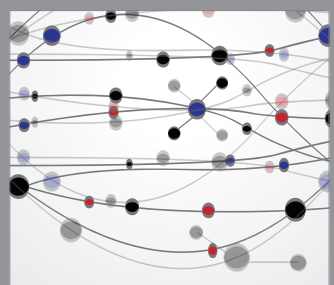

The Scientific World Journal
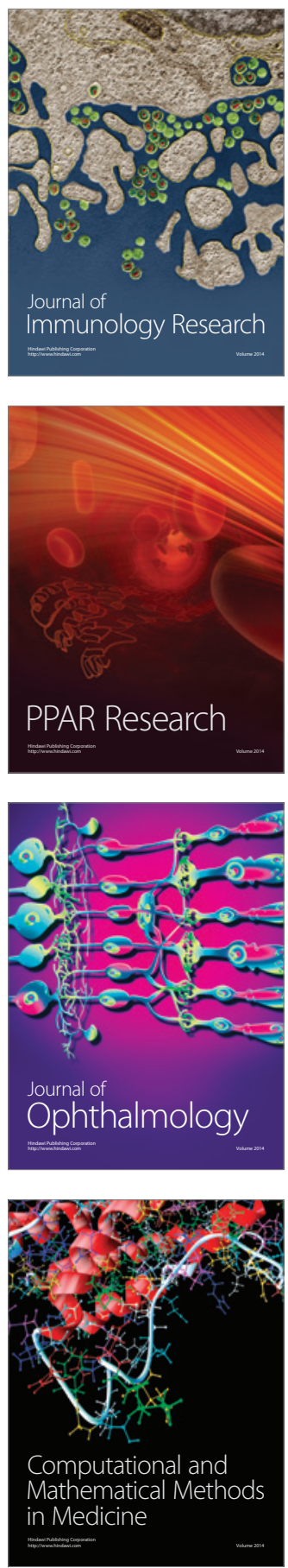

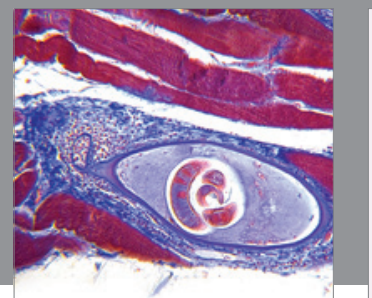

Gastroenterology

Research and Practice
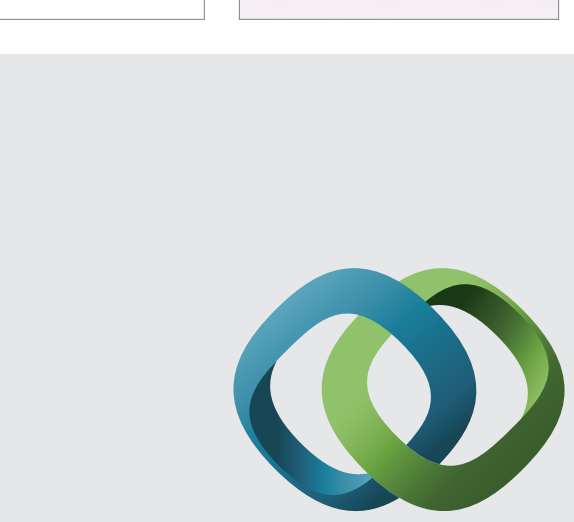

\section{Hindawi}

Submit your manuscripts at

http://www.hindawi.com
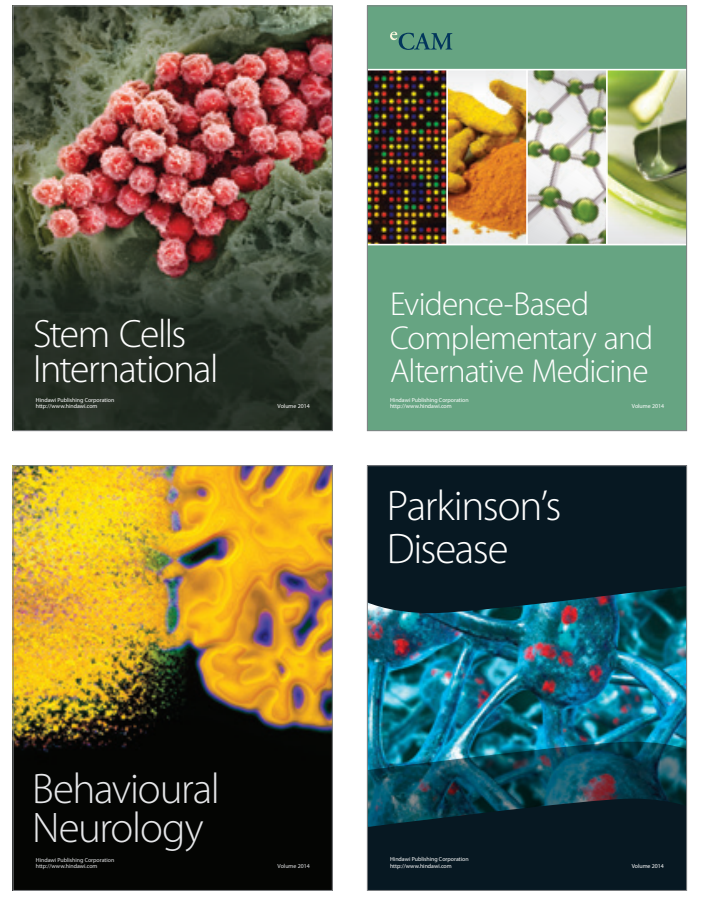
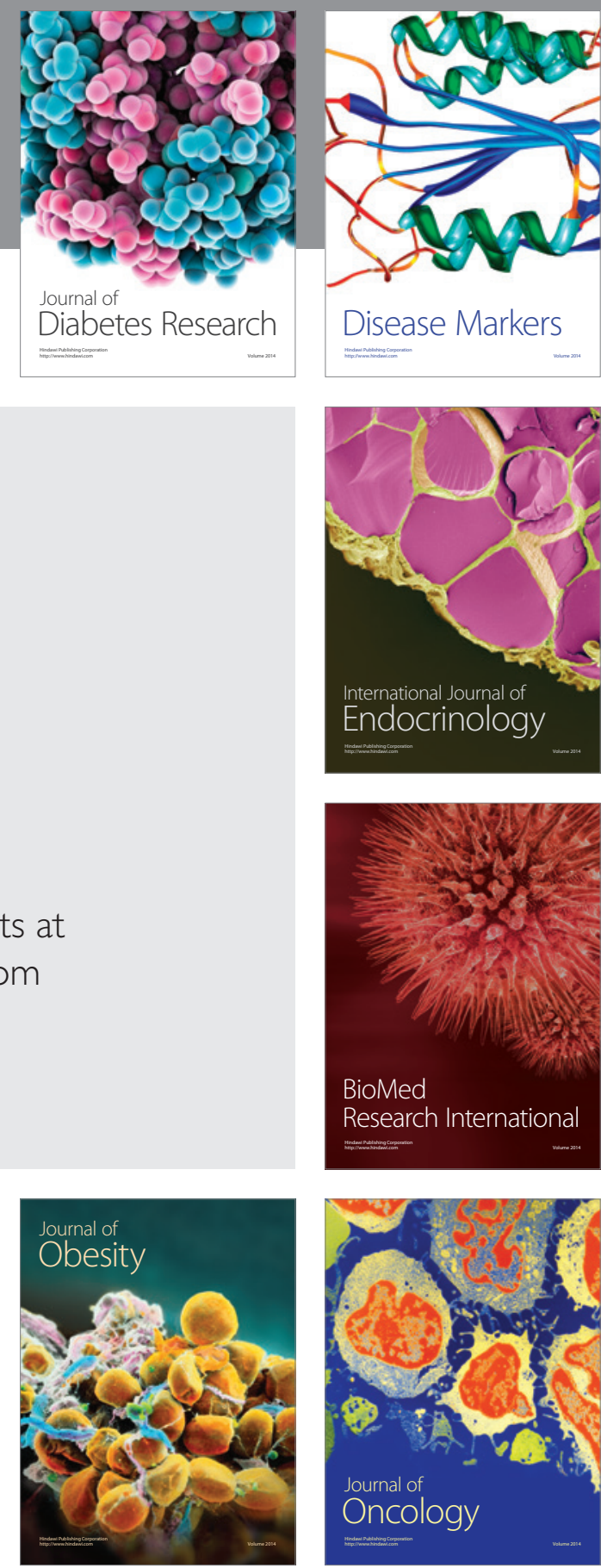

Disease Markers
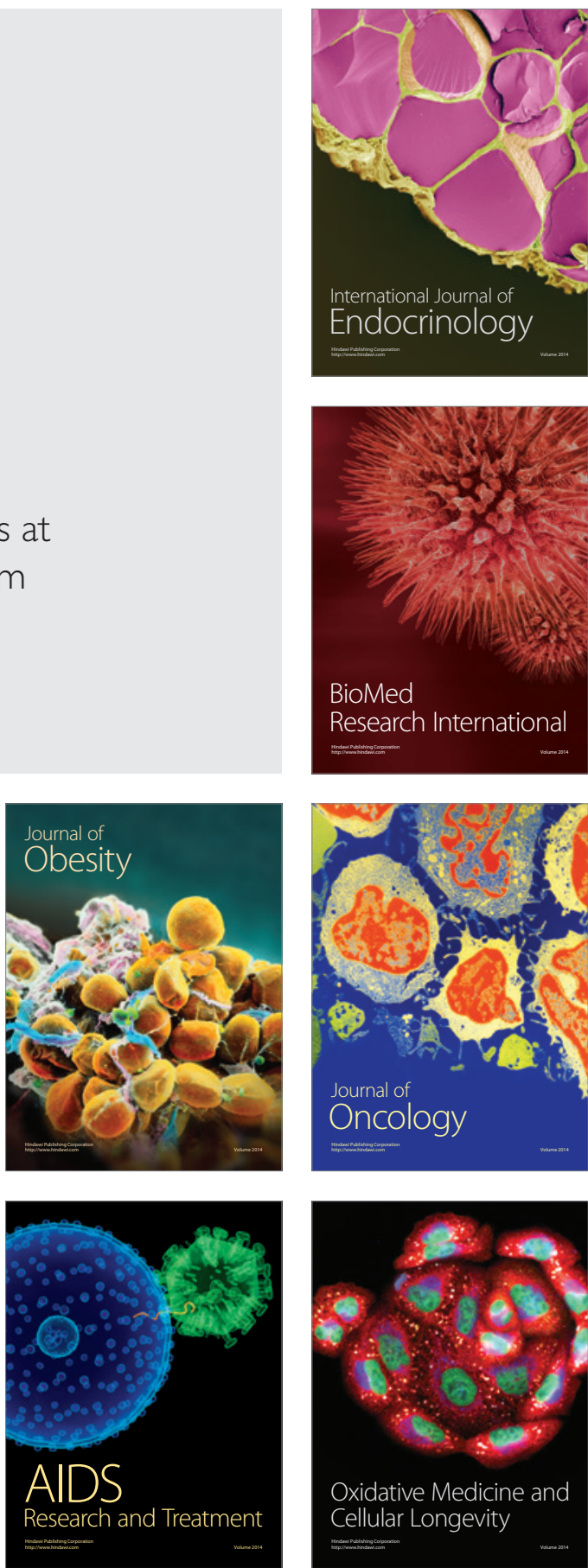